OPEN ACCESS

Edited by: Nicola Giuliani, Università degli Studi di Parma, Italy

Reviewed by: Giacomina Brunetti, Università degli studi di Bari Aldo Moro, Italy Ajaikumar B. Kunnumakkara, Indian Institute of Technology

Guwahati, India

${ }^{*}$ Correspondence:

Yu-Tzu Tai

yu-tzu_tai@dfci.harvard.edu;

Kenneth C. Anderson kenneth_anderson@dfci.harvard.edu

Specialty section:

This article was submitted to

Cancer Immunity and

Immunotherapy,

a section of the journal

Frontiers in Immunology

Received: 04 June 2018

Accepted: 24 July 2018

Published: 10 August 2018

Citation:

Tai Y-T, Cho S-F and Anderson KC (2018) Osteoclast

Immunosuppressive Effects in

Multiple Myeloma: Role of Programmed Cell Death Ligand 1.

Front. Immunol. 9:1822. doi: 10.3389/fimmu.2018.01822

\section{Osteoclast Immunosuppressive Effects in Multiple Myeloma: Role of Programmed Cell Death Ligand 1}

\author{
Yu-Tzu Tai ${ }^{1 *}$, Shih-Feng Cho ${ }^{1,2,3}$ and Kenneth C. Anderson ${ }^{1 *}$ \\ ${ }^{1}$ LeBow Institute for Myeloma Therapeutics and Jerome Lipper Multiple Myeloma Center, Dana-Farber Cancer Institute, \\ Harvard Medical School, Boston, MA, United States, ${ }^{2}$ Division of Hematology \& Oncology, Department of Internal Medicine, \\ Kaohsiung Medical University Hospital, Kaohsiung Medical University, Kaohsiung, Taiwan, ${ }^{3}$ Faculty of Medicine, College of \\ Medicine, Kaohsiung Medical University, Kaohsiung, Taiwan
}

Immunomodulatory drugs and monoclonal antibody-based immunotherapies have significantly improved the prognosis of the patients with multiple myeloma (MM) in the recent years. These new classes of reagents target malignant plasma cells (PCs) and further modulate the immune microenvironment, which prolongs anti-MM responses and may prevent tumor occurrence. Since MM remains an incurable cancer for most patients, there continues to be a need to identify new tumor target molecules and investigate alternative cellular approaches using gene therapeutic strategies and novel treatment mechanisms. Osteoclasts (OCs), as critical multi-nucleated large cells responsible for bone destruction in $>80 \%$ MM patients, have become an attractive cellular target for the development of novel MM immunotherapies. In MM, OCs are induced and activated by malignant PCs in a reciprocal manner, leading to osteolytic bone disease commonly associated with this malignancy. Significantly, bidirectional interactions between OCs and MM cells create a positive feedback loop to promote MM cell progression, increase angiogenesis, and inhibit immune surveillance via both cell-cell contact and abnormal production of multiple cytokines/chemokines. Most recently, hyper-activated OCs have been associated with activation of programmed cell death protein 1 (PD-1)/ programmed cell death ligand 1 (PD-L1) pathway, which impairs T cell proliferation and cytotoxicity against MM cells. Importantly, therapeutic anti-CD38 monoclonal antibodies and checkpoint inhibitors can alleviate OC-induced immune suppression. Furthermore, a proliferation-inducing ligand, abundantly secreted by OCs and OC precursors, significantly upregulates PD-L1 expression on MM cells, in addition to directly promoting MM cell proliferation and survival. Coupled with increased PD-L1 expression in other immune-suppressive cells, i.e., myeloid-derived suppressor cells and tumor-associated macrophages, these results strongly suggest that OCs contribute to the immunosuppressive MM BM microenvironment. Based on these findings and ongoing osteoimmunology studies, therapeutic interventions targeting $\mathrm{OC}$ number and function are under development to diminish both MM bone disease and related immune suppression. In this review, we discuss the classical and novel roles of OCs in the patho-immunology of MM. We also describe novel therapeutic strategies simultaneously targeting OCs and MM interactions, including PD-1/PD-L1 axis, to overcome the immune-suppressive microenvironment and improve patient outcome.

Keywords: multiple myeloma, osteoclast, bone marrow microenvironment, osteoblast, programmed cell death 1, programmed cell death ligand 1, immunotherapy 


\section{INTRODUCTION}

Multiple myeloma (MM), a malignancy of plasma cells (PCs), is defined by abnormal growth of malignant PCs within the bone marrow (BM), resulting in excessive monoclonal immunoglobulin in the blood and urine, impaired renal function, and repeated infections in patients (1). Moreover, osteolytic bone disease is a central hallmark of MM, which severely impacts quality of life in $>80 \%$ of patients $(2,3)$. Specifically, osteoclast (OC)-mediated lytic bone destruction remains a cause of major morbidity in MM. In the past two decades, the introduction of autologous stem-cell transplantation and the availability of novel agents with different mechanisms of action including proteasome inhibitors (e.g., bortezomib, carfilzomib, ixazomib) and immunomodulatory drugs (IMiDs) (e.g., thalidomide, lenalidomide, pomalidomide) have revolutionized the therapeutic strategies for MM and significantly prolonged overall survival of patients (4-7). However, cure is rarely achieved due to the development of drug resistance and persistence of minimal residual disease. Thus, there is unmet need for innovative treatment modalities to eradicate residual tumor clones and effectively prevent disease relapses, as well as enhance overall anti-MM immunity.

Recently, immunotherapies have showed significant clinical activities not only against malignant, PCs but also potentially relieving the immunocompromised status in MM. Currently, a variety of immunotherapeutic strategies are under intensive preclinical and clinical development, including monoclonal antibodies (mAbs), chimeric antigen receptor $\mathrm{T}$ (CAR $\mathrm{T}$ ) cells, immune checkpoint inhibitors, and as well as cancer vaccines (8). Following the approval of the first two mAbs daratumumab targeting CD38 and elotuzumab targeting SLAMF7 by FDA in late 2015 for the treatment in relapse and refractory MM (RRMM), multiple combination trials of these two mAbs are ongoing (8, 9). Excitingly, daratumumab has also shown clinical responses in newly diagnosed MM patients (9). Another therapeutic anti-CD38 mAb isatuximab, unlike daratumumab, can directly kill MM cells with p53 mutations and in the absence of effector natural killer (NK) cells in vitro (10). Indeed, isatuximab, when combined with lenalidomide or pomalidomide plus dexamethasone, also demonstrated significant activity in heavily treated $\operatorname{RRMM}(11,12)$. Isatuximab is currently undergoing studies for the treatment of relapsed and previously untreated MM patients, pursuing FDA approval. Most importantly, more than a dozen targeted immunotherapies besides CD38 and SLAMF7 mAbs, alone or in combinations with current or emerging anti-MM therapies with different mechanisms of actions, have already entered clinical investigations.

Accumulating data for the past two decades has confirmed that the BM microenvironment plays a crucial role in the pathogenesis and recurrence of MM $(13,14)$. Malignant PCs in the MM BM are in close contact with non-myeloma cells, including bone marrow stromal cells (BMSCs) $(13,15)$, osteoclasts (OCs) (16-20), myeloid-derived suppressor cells (MDSCs) $(21,22)$, tumor-associated macrophages (TAMs) (23), regulatory T-cells (Treg) $(21,24,25)$, plasmacytoid dendritic cells (pDC) (26), and regulatory B-cells (Breg) (27). These BM accessory cells, alone or in collaboration with others, support the initiation, progression, and re-occurrence of MM. They further influence treatment responses and may promote clonal evolution of malignant PC clones to adapt to the immune microenvironment and escape immune surveillance. For example, MM cells increase their proliferation upon adherence to BMSCs and become resistant to dexamethasone treatment $(13,28)$. Cytotoxic effects of some conventional drugs, i.e., dexamethasone, melphalan, as well as antibody-mediated cellular cytotoxicity against MM cells are reduced in the presence of BMSCs $(13,29)$.

Among other abovementioned cells, hyperactive OCs cause osteolytic bone diseases affecting almost every MM patient, thereby making them a potential novel cellular target for novel therapeutics. OCs, critical mediators of bone absorption, are large cells with multiple nuclei derived from CD14+ lineage myeloid cells (i.e., monocyte, macrophage) under the influence of several OC-activating cytokines produced by multiple BM accessory cells. Among many OC-stimulating cytokines, macrophage-colony-stimulating factor (M-CSF) and receptor activator of nuclear factor- $\mathrm{\kappa B}(\mathrm{NF}-\mathrm{\kappa B})$ ligand (RANKL) are two essential OC-differentiation factors during osteoclastogenesis. Traditionally, OCs are known to play a vital role in maintenance of bone metabolism by counteracting osteoblasts (OBs). In contrast to OBs, which produce and secrete matrix proteins and transport mineral into the matrix for bone formation, OCs are responsible for bone degradation by breaking down tissues. In addition to inducing growth and survival of MM cells, OCs are capable of regulating growth of other BM cells, such as hematopoietic stem cells and B cell progenitors (30-32). Moreover, a close crosstalk exists between skeletal and immune systems, termed osteoimmunology, since several regulatory molecules are shared by these two systems (33-35). Most recently, OCs have been further associated with maintenance of immunosuppressive MM BM microenvironment via induction and secretion of several immune checkpoint proteins from OCs in close contact with MM cells (20) (Figure 1).

Programmed cell death ligand 1, also known as cluster of differentiation 274 (CD274) or B7 homolog $1(\mathrm{~B} 7-\mathrm{H} 1)$, is a $40 \mathrm{kDa}$ type 1 transmembrane protein encoded by the CD274 gene located in the 9p24.1 region with the full length of cDNA $870 \mathrm{bp}$ in man $(36,37)$. Following binding to its cognate receptor programmed cell death protein 1 (PD-1) (CD279) expressed on activated T cells, B cells, NK cells, and monocytes, the PD-1/ PD-L1 pathway inhibits immune activation by triggering the phosphatases that deactivate signals emanating from the $\mathrm{T}$ cell receptor (38-40). Specifically, the engagement of PD-L1 with PD-1 on activated T cell leads to $\mathrm{T}$ cell dysfunction, exhaustion, neutralization, and production of interleukin-10 (IL-10) (41, 42). PD-L1 also interacts with B7-1 (CD80) on activated T cells, which in turn downregulates $\mathrm{T}$ cell activity (43). This important checkpoint pathway has been associated with autoimmune disease, infection, and cancer $(37,44-46)$.

In the tumor microenvironment, $\mathrm{PD}-1 / \mathrm{PD}-\mathrm{L} 1$ pathway performs a vital role in tumor progression and survival by escaping tumor neutralizing immune surveillance. PD-L1 is expressed on various tumor cells and antigen-presenting cells (APCs) (41). PD-L1 overexpression on tumor cells is further associated with higher risk of cancer progression and poor clinical outcome 


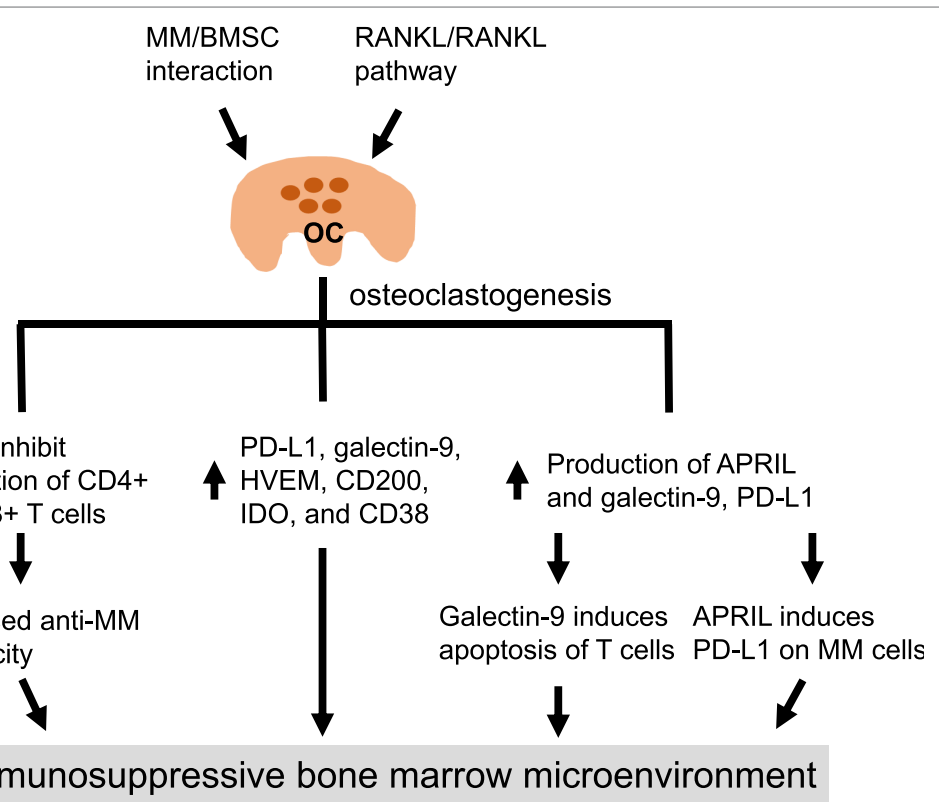

FIGURE 1 | Osteoclasts create an immunosuppressive microenvironment in multiple myeloma (MM). In MM, the interaction of MM cells and bone marrow stromal cells induces production of various cytokines and growth factors, as well as activates RANK/receptor activator of nuclear factor- $\mathrm{BB}$ (NF- $\mathrm{kB}$ ) ligand pathway, to promote the differentiation and expansion of OCs from CD14+ OC precursors. OCs can directly inhibit proliferation of activated CD4+ and CD8+ effector T cells, thereby reducing their numbers and leading to decreased MM cell lysis. The expression of multiple immune checkpoint molecules on OCs is increased during osteoclastogenesis. Furthermore, the secretion of galectin-9 and APRIL is significantly augmented during OC formation, resulting in apoptosis of T cells, i.e., mediated by galectin-9, and enhanced programmed cell death ligand 1 expression on MM cells, i.e., mediated by APRIL, IL-6. APRIL, a proliferation-inducing ligand; BMSC, bone marrow stromal cell; HVEM, herpesvirus entry mediator; IDO, indoleamine 2, 3-dioxygenase.

(47-49). Importantly, immune checkpoint inhibitors targeting PD-1/PD-L1 have generated groundbreaking and durable responses in a broad spectrum of advanced solid tumors (50) and blood cancers including B-cell lymphomas $(51,52)$. In MM, PD-1/PD-L1 is also activated and associated with immunocompromised status and drug resistance $(53,54)$, supporting the development of new treatments targeting this pathway in MM (55). Despite inconclusive early clinical reports $(51,55)$, this important immune checkpoint pathway may still represent one of the novel strategies with potential anti-MM activities targeting defective immune effector cells, when combined with current and emerging therapies for MM.

We here summarized mechanisms of myeloma bone diseases and the novel functional characterization of OCs in the immunosuppressive BM microenvironment in MM via PD-1/PD-L1 pathway. Also included are effects of various current and emerging anti-MM treatments on OCs, other cellular subtypes associated the MM bone disease, and immune cells in the BM. Finally, we discuss the novel strategies for immune-therapies targeting $\mathrm{OC}$ function and PD-1/PD-L1 pathway in combination with other MM treatments to further overcome OC-induced immune suppression and prolong overall treatment responses.

\section{MYELOMA BONE DISEASE: CLINICAL MANIFESTATION}

The cells in skeletal system including OBs, OCs, and osteocytes closely communicate with each other to maintain the balance of bone metabolism. OBs provide essential signals, M-CSF, RANKL, and other co-stimulatory factors, to promote the differentiation of myeloid lineage precursors of OCs (56). However, this balance is significantly disturbed in the majority of MM patients, in whom OCs are highly activated accompanied with little or no OB activity (2). Eventually, increased bone-degrading effects accelerate osteoporosis and the development of lytic bone lesions, shown as characteristic "punched-out" lesions on skeletal X-ray $(57,58)$.

Clinically, approximately $80 \%$ of MM patients have radiologic evidence of bone involvement, and 90\% have osteolytic manifestations including generalized osteopenia or discrete lytic lesions over the course of disease $(16,59)$. The most commonly involved sites include vertebral bodies (49\%), skull (35\%), pelvis (34\%), and ribs (33\% of patients) $(2,3,60)$. Patients with MM bone disease may suffer from skeletal-related events (SREs) including pain, pathological fractures, spinal cord compression, and hypercalcemia. Furthermore, these SREs may increase mortality, decrease quality of life, and result in an adverse outcome $(58,61)$.

\section{MYELOMA BONE DISEASE: MAJOR CELLULAR AND MOLECULAR MECHANISMS}

The mechanisms of MM-related bone disease involve overactivation of OCs and inhibition of OBs via complicated interactions between various BM cells and cytokines secreted by them (2). The contact between MM cells and BMSCs significantly increases 
activity and accelerates differentiation of OCs, while inhibiting the growth of OBs $(15,62)$. For example, the binding of surface VLA-4 ( $\alpha_{4} \beta_{1}$ integrin) on MM cells to VCAM- 1 on BMSCs induces production of cytokines, which favor bone absorption including: RANKL, M-CSF, IL-1, and IL- 6 by BMSCs; and OC-activating factors including macrophage inflammatory protein- $1 \alpha / \beta$ (MIP$1 \alpha / \beta)$, IL-3, stromal-derived factor- $1 \alpha$, and tumor necrosis factor $\alpha$ (TNF- $\alpha)$ by MM cells(63-70). In addition, adhesion between MM cells and BMSCs promotes secretion of B-cell activation factor (BAFF), which also promote growth of MM cells $(71,72)$ and RANKL-independent proliferation of OCs (72). In parallel, p38 mitogen-activated protein kinase signaling pathway is activated upon MM cell adherence to BMSCs, leading to more secretion of MM cell-supportive factors IL-6 and vascular endothelial growth factor (VEGF), in addition to induction of OC-activating factors (i.e., IL-11, RANKL, MIP-1 $\alpha$ ) (73). Moreover, IL-6 secretion by BMSC enhances expression and secretion of matrix metalloproteinase-13 (MMP-13) in MM cells (74). MMP-13, in turn, promotes fusion of OCs and bone absorption. Simultaneously, activated OCs support proliferation of MM cells by secreting more factors including annexin-II, osteopontin (OPN), IL-6, IL-10, insulin growth factor-1, BAFF, and a proliferation-inducing ligand (APRIL) (13, 20, 75-78).

In contrast, the expansion and activation of OBs is significantly blocked in MM bone disease due to increased secretion of OB inhibitory factors including: dickkopf-1 (Dkk-1), soluble frizzled-related protein 2 (sFRP2), sFRP3, IL-3, IL-7, growth factor independence-1 (gfil), hepatocyte growth factor, activin A, sclerostin, and TNF- $\alpha(2,62,79-84)$. These factors directly and indirectly block proliferation and differentiation of OBs, impairing mineral deposition and bone regeneration. In addition, osteoprotegerin (OPG), a soluble decoy receptor of RANKL, is produced by OBs and inhibits OC activation under normal physiological conditions. OPG levels are significantly decreased in MM bone disease (85), associated with reduced OB number. Defective bone formation due to decreased proliferation and differentiation of OBs induced by MM cells, along with reduced levels of OC inhibitory cytokines produced by OBs, further augments $\mathrm{OC}$ formation and induction of osteolytic bone destruction.

In terms of signaling transduction cascades, the RANK/ RANKL pathway critically regulates MM-induced bone lesions since several of the abovementioned OC-activating factors are induced via this pathway. RANKL is detected on the surface of MM cells and elevated in MM patients compared with health individuals and patients with monoclonal gammopathy of undetermined significance (MGUS) $(86,87)$. Concurrently, increased OCs induced by RANKL activate dormant MM cells (32). In fact, higher RANKL expression is associated with more severe bone disease and poorer clinical outcome $(86,88)$. In addition, MM cells express mRNA encoding the isoform of soluble RANKL (sRANKL), which directly promotes activation of OCs (89). Significantly, sRANKL is elevated in MM patients and closely related to generalized bone loss $(90,91)$.

Further studies on OC-gene expression profiling identify genes coding for 4 CCR2-targeting chemokines and genes coding for MM growth factors to be highly expressed by MM OCs (92).
Specifically, higher CCR2 expression in MM cells is correlated with increased bone lesions, and CCR2 chemokines activate mitogen-activated protein kinase (MEK) pathway to support growth of MM cells (92). These results implicate the MEK1/2 signaling cascade (93), which is significantly induced by M-CSF and RANKL, in the pathogenesis of MM bone disease $(17,18,94)$.

\section{OCs IN THE MM BM MICROENVIRONMENT}

The suppression of the host immune system is a critical step in the progression of many cancers, including MM. The interaction of MM cells and surrounding cells promotes production of immunosuppressive cytokines, growth of immune-suppressive cell populations, and suppression of the anti-MM ability of normal immune cells. For example, IL-6 and IL-10 levels are increased in the serum samples of MM patients, and both cytokines promote MM cell growth and survival in an autocrine and paracrine fashion. These two cytokines are also critical in MM-related immunosuppression, since IL-10 has potent immunosuppressive ability by inhibiting production of pro-inflammatory interferon- $\gamma$ (IFN- $\gamma$ ) and TNF- $\alpha$ in immune effector cells (95), and IL-6 has been linked to impaired NK cell activity (96). Furthermore, the pro-osteoclastogenic LIGHT/TNFSF14 was recently linked to MM-bone disease (97). At the cellular level, inhibitory immune $\mathrm{T}$ regulatory cells (Tregs), B regulatory cells, and $\mathrm{pDCs}$ are significantly increased in the BM of the patients with active MM $(24,26,27)$. In parallel, MM cells induce the development of myeloid-derived suppressor cells (MDSCs), which in turn support proliferation of MM cells by promoting proliferation of Tregs and suppressing T-cell-mediated immune responses (22, 98). Importantly, MDSCs induced by MM cells can further differentiate into mature OCs capable of inducing bone lysis, which further links immune suppression and hyper-active bone lysis activity of MDSCs in MM progression (99). Furthermore, the increased percentage of circulating pre-OCs have been described in $\operatorname{MM}(100,101)$.

The MM BM microenvironment is also characterized by increased angiogenesis, which further suppresses anti-MM immunity. Specifically, contact of MM cells and OCs enhances angiogenesis and production of angiogenic factors (VEGF and OPN), which in turn promote the expansion of OCs by vascular endothelial cells (102). Both VEGF and OPN have been shown to directly induce proliferation of MM cells. In addition, increased OC formation by stimulation of RANKL or parathyroid hormone-related protein promotes angiogenesis via induction of MMP-9, a potent angiogenic factor secreted by OC mediating RANKL-induced angiogenesis. In contrast, OPG inhibits formation of OCs and decreases formation of new vessels (103).

Most recently, OCs have been shown to significantly block $\mathrm{T}$ cell proliferation and cytotoxicity in MM cells (Figure 2 ). The expression of several immune checkpoint molecules on OCs, including PD-L1, galectin-9, herpesvirus entry mediator, CD200, T-cell metabolism regulators indoleamine 2, 3-dioxygenase (IDO), and CD38, is significantly enhanced during OC formation in vitro (20) (Figure 1). Meanwhile, the secretion of galectin-9 


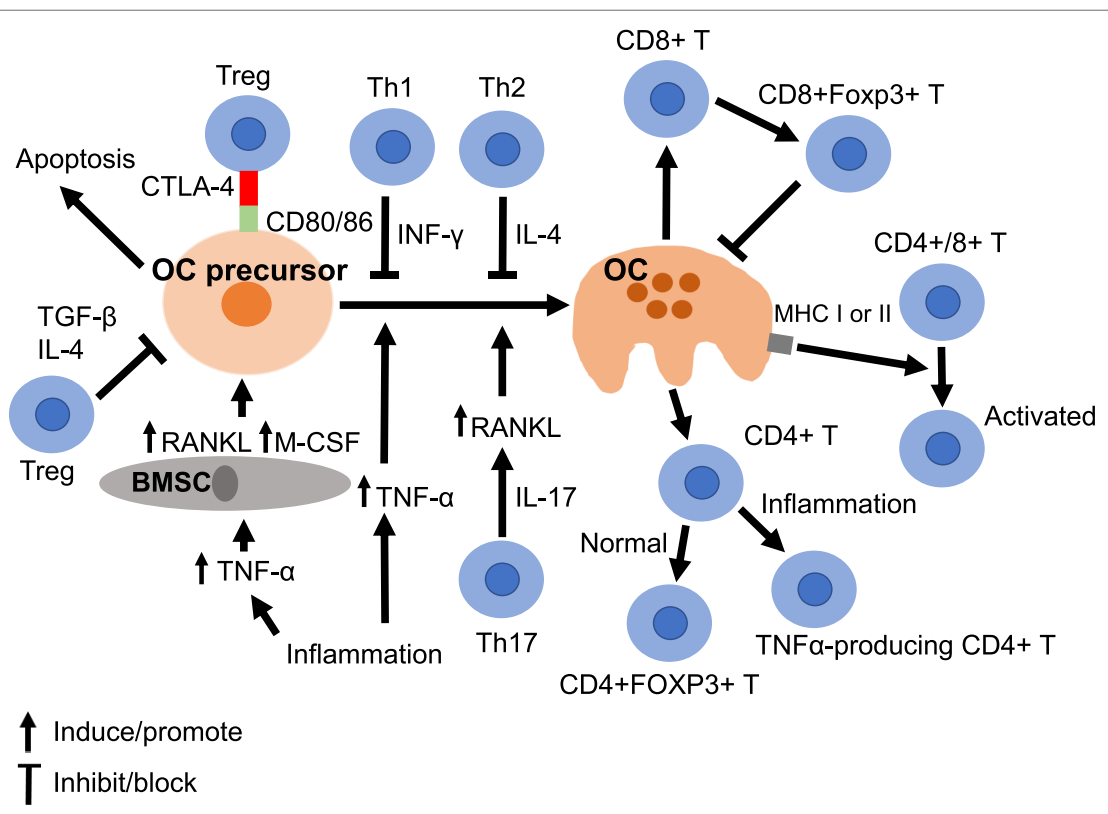

FIGURE 2 | Osteoclasts crosstalk with immune cells. The differentiation of OCs from its precursor (OC precursor) is mediated by multiple cytokines. For example, inflammation induces production of tumor necrosis factor $\alpha$ (TNF $\alpha$ ), which activates OC formation directly or indirectly via BMSC. Another immune cell, the Th17 cell,

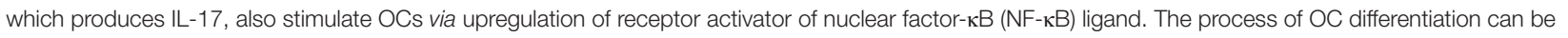
inhibited by INF- $\gamma$ and IL4 produced by Th1 and Th2 cells, respectively. In parallel, T regulatory cells (Tregs) can inhibit OC precursors by secretion of TGF- $\beta$ and IL-4. CTLA 4 expressed on Tregs can bind to CD80/86 on OC precursors and further influence the fate of OC precursors. OCs can activate several immune cells. First, OCs induce formation of CD8+FOXP3+ T cells, which in turn inhibit OCs. Second, OCs can act as antigen-presenting cells to promote immune response of CD4 or CD8 T cells. Third, OCs can induce differentiation of CD4+ T cell to TNF $\alpha$-producing cells or CD4+FOXP3+ T cells, dependent on the surrounding microenvironment. BMSC, bone marrow stromal cell; IL, interleukin; INF, interferon; M-CSF, macrophage-colony-stimulating-factor; TGF, tumor growth factor; TNF, tumor necrosis factor; Treg, regulatory $T$ cell.

and APRIL by OCs is significantly increased. Galectin-9 significantly induces apoptosis of T cells, and APRIL further induces expression of PD-L1 on MM cells mainly via MEK/ERK pathway. Significantly higher expression of PD-L1 was observed on OCs than MM cells, which was linked to profound inhibition of T cell activation to lyse MM cells. Importantly, the inhibition of T cell activation can be repaired using blocking PD-L1 or anti-CD38 monoclonal antibody (20), suggesting potential clinical development of these mAbs, alone and in combination, to overcome the immunosuppressive MM BM milieu.

\section{OCs IN OSTEOIMMUNOLOGY}

The skeletal and immune systems closely interact, since cytokines produced by lymphocytes significantly affect bone homeostasis. Among cells in these two systems, OCs significantly regulate intricate cytokine and cellular networks, as described above and in Figure 2. OCs interact not only with various BM cytokines but also control differentiation and expansion of multiple immune subsets. For example, inflammation or immune-related cytokines like TNF- $\alpha$, IL-1, and IL-6, are associated with bone absorption (104-107). In autoimmune diseases like rheumatoid arthritis, production of cytokines (TNF- $\alpha$, IL-1, IL-6, IL-17) is significantly increased in synovium and pannus, which may directly affect bone by upregulating OC activities at sites of articular erosion (108). In fact, TNF- $\alpha$ induces activation of OCs indirectly by enhancing the expression of RANKL and M-CSF in BMSCs or directly by interacting with OC precursors (109).

As for the interaction between OCs and immune cells, activated CD3+ or CD4+ T cells with RANKL expression support differentiation of OC in vitro $(110,111)$. A subset of CD4+ T cells (Th17), which produces IL-17 could upregulate RANKL and promote differentiation of OCs by the effect of IL-17 on BMSCs and OCs (112). T cells also produce IL-7, which can promote formation of OCs by upregulating RANKL (113). In addition, activated $\mathrm{T}$ cells secrete soluble RANKL (sRANKL), which is correlated with the formation of OCs and bone loss $(114,115)$. On the other hand, the activation of OCs can be downregulated by IFN $\gamma$ and IL- 4 secreted by Th 1 and Th 2 cells, respectively. IFN$\gamma$ produced by $\mathrm{T}$ cells significantly suppresses differentiation of OCs by interfering with the RANKL-RANK pathway, including degradation of downstream molecules such as tumor necrosis factor receptor-associated factor 6 (TRAF6) (116).

On the other hand, human OCs can function as APCs by expressing class I and II MHC molecules and co-stimulatory molecules to in turn activate both CD4+ and CD8+ T cells (117). In a mouse model study, expression of RANKL was detected on the surface of activated CD4+ and CD8+ T cells (118). Conversely, inhibition by a RANKL inhibitor suppresses activation of T cells, suggesting the role of RANK/RANKL pathway in T cell activation. Meanwhile, OCs are capable of inducing differentiation of CD8+ T cells into FoxP3+ CD8+ Tregs, which not only decrease 
antigen-specific $\mathrm{T}$ cell proliferation but also suppress bone resorption by forming a negative feedback loop (119-123). In a similar fashion, adoptive transfer of CD4+CD25+ Tregs into T-cell deficient mice enhances bone mass formation accompanied by decreased OC numbers, partially mediated by IL- 4 and IL-10 (124). In addition, isolated human Tregs suppress OC differentiation via the secretion of TGF- $\beta$ and IL-4 (125). CD4+CD25+Foxp3+ Treg can also inhibit differentiation of OCs by cytotoxic T lymphocyte antigen 4 (CTLA4) in a cell-to-cell contact-dependent manner $(126,127)$. Specifically, CTLA4 on Tregs downregulates proliferation of OCs by binding to CD80/86 on OC precursors (128). The engagement of CD80/86 by CTLA-4 in OC precursors activates IDO, which in turn further degrades tryptophan and induces apoptosis of OC precursors.

$A$ recent study in a mouse model showed that OCs derived from normal $\mathrm{BM}$ can induce $\mathrm{CD} 4+\mathrm{FoxP} 3+$ regulatory $\mathrm{T}$ cells (129). On the contrary, OCs can induce TNF $\alpha$-producing CD4+ $\mathrm{T}$ cells in an inflammatory bowel disease mouse model (129). All these findings suggest that OCs not only play a role in immune suppression, but also serve as true APCs depending on the origin and environment.

\section{PD-L1 EXPRESSION ON MM CELLS AND OCs}

Programmed cell death protein 1/PD-L1 pathway contributes to tumor progression and survival by escaping tumor neutralizing immune surveillance in the tumor microenvironment (130). PD-L1 has been linked to the maintenance of Tregs, which are associated with suppression of antitumor immune response (131). The expression of PD-L1 on tumor cells can be enhanced by IFN $\gamma$ secreted by activated cytotoxic $\mathrm{T}$ cells in the tumor microenvironment, thereby downregulating antitumor immunity (132). In addition, PD-L1 expression can be altered by extrinsic factors like inflammatory cytokines, which induce signaling cascades including MEK/ERK, PTEN, mTOR, or PI3K pathways (133-135).

In MM, PD-L1 is expressed on PCs isolated from patients with MM and MM cell lines, but not on normal PCs (20, 133, 136-138). The percentages of PD-L1 + PCs are higher on MM and smoldering MM than MGUS (133). Increased PD-L1 levels in MGUS patients is further linked to a higher risk of progression to clinical MM (139). PD-L1 expression on MM cells is enhanced following stimulation of IFN $\gamma$ via activation of MYD88, TRAF6, and MEK/ERK signaling pathways; conversely, MEK1/2 inhibitors partially block IFN $\gamma$-induced PD-L1 upregulation $(20,133)$. BMSCs also induce expression of PD-L1 on MM cells by production of IL-6 via signal transducer and activator of transcription 3, MEK1/2, or Janus kinase $2(140,141)$. In addition, MM cells with PD-L1 expression are correlated with higher proliferation rate and higher expression of BCL-2 and FasL than MM cells without PD-L1 expression. Moreover, the interaction between PD-L1 on MM cells and PD-1 not only inhibited tumor-specific cytotoxic $\mathrm{T}$ cells but also promoted drug resistance in myeloma cells through the PI3K/AKT signaling cascade (53). Importantly, higher serum level of soluble PD-L1 in MM patients is associated with shorter progression-free survival (142).
Programmed cell death ligand 1 is expressed on multiple immune cell subsets in the MM BM microenvironment, including pDCs (137, 143), MDSCs (141), and OCs (20). Specifically, PD-L1 on pDCs is overexpressed in $81 \%$ of cases (143). Expression of PD-L1 is significantly higher on the CD141+ subset, which regulates immune response of CD8+ T cells, than on the CD141-negative CD4+ T cells. PD-L1 on immunosuppressive MDSCs is increased in patients with RRMM compared with newly diagnosed MM (141). Significantly, blockade of PD-1/ PD-L1 pathway inhibits MDSC-mediated growth of MM cells. Furthermore, BM mesenchymal stem cells promote proliferation and reduce apoptosis of MM cells by suppressing T-cell immune responses via PD-1/PD-L1 pathway (144).

Furthermore, OCs induce expression of PD-L1 on MM cells in an APRIL-dependent manner via binding of two APRIL receptors (BCMA and TACI), which are highly expressed on MM cells $(20,145)$ (Figure 3). Since OCs are the key physiological source of APRIL production in the BM microenvironment, these results further provide evidence of a positive feedback loop between OCs and MM cells in promoting PD-L1-mediated immunosuppression in MM. Meanwhile, increased PD-L1 expression on OCs further enhances immunosuppression by promoting the binding of PD-1 on T cells and inducing dysfunction and apoptosis of effector T cells (20).

Some current and emerging anti-MM agents can affect the expression of PD-L1 on MM cells (Table 1). For example, proteasome inhibitors, oncolytic reovirus, and a histone deacetylase inhibitor 6 (HDAC) inhibitor have been shown to enhance PD-L1 expression on MM cells (146-148). On the other hand, lenalidomide and MEK1/2 inhibitors, as well as APRIL blocking reagents, reduce PD-L1 induction on MM cells (20, 133, 141, 145, 149). These findings support further investigations targeting PD-L1 in MM.

\section{TARGETING PD-1/PD-L1 PATHWAY WITH VARIOUS CURRENT AND NOVEL MM TREATMENTS}

\section{Preclinical Studies}

The combination of hematopoietic stem cell transplantation with whole-cell vaccination and PD-L1 blockade significantly improves the survival of MM-bearing mice (136). In another study where anti-MM activity is mainly mediated by pre-activated T cells, the combination of anti-PD-L1 inhibitor plus lymphodepletion by sublethal dose of radiation augments T-cell-mediated anti-MM effect and significantly improves survival of mice (54).

A combination of PD-1/PD-L1 blockade with IMiDs was also investigated in a study where NK cells or $\mathrm{T}$ cells were cocultured with CD138+ tumor cells isolated from MM patients and treated with PD-1or PD-L1 inhibitor, alone or together, and with lenalidomide (141). The immune checkpoint blockade by PD-1 or PD-L1, or PD-1/PD-L1 inhibitor combination, induced effector cell-mediated anti-MM cytotoxicity (137, 141). The expression of PD-1 and PD-L1 on effector cells and MM cells was downregulated by lenalidomide. Lenalidomide further augments anti-MM cytotoxicity mediated by checkpoint 


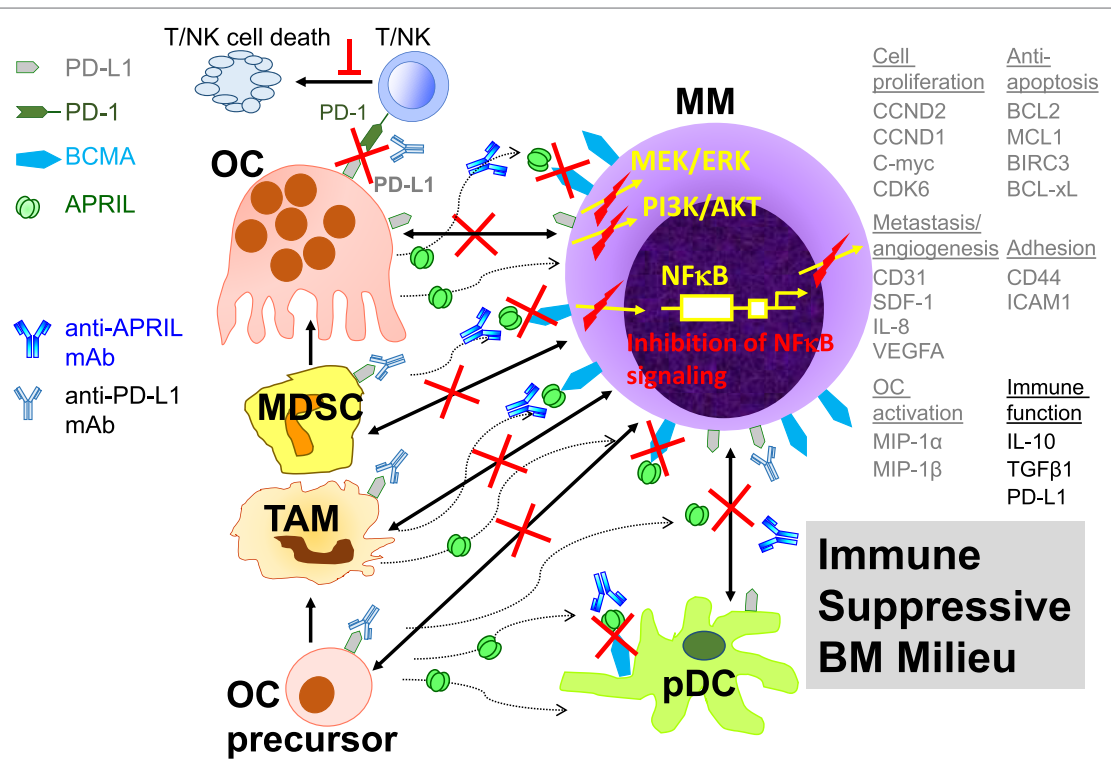

FIGURE 3 | Targeting a proliferation-inducing ligand (APRIL) and programmed cell death ligand 1 (PD-L1) to overcome OC-mediated immune suppression in the multiple myeloma (MM) BM milieu. APRIL is secreted by myeloid lineage cells including OCs, OC precursors, tumor-associated macrophages, and MDSCs, in the BM. MDSCs induced by MM cells further differentiate into functional OCs. Besides the induction of critical downstream targets (listed in gray on the right), APRIL induces PD-L1 on MM cells via BCMA, a specific MM antigen. This positive feedback loop between MM cells and MM-supporting cells, coupled with increased PD-L1 expression, further inhibits effector-mediated MM cell lysis via binding to programmed cell death protein 1 (PD-1) on activated T and natural killer (NK) effector cells. Blocking PD-1/PD-L1 and APRIL monoclonal antibodies prevent these effects and may mitigate immune suppression in MM. Adapted from Ref. (20, 145). TAM, tumor-associated antigen; MDSC, myeloid-derived suppressor cells; BCMA, B cell maturation antigen; T/NK, immune effector cells; pDC, plasmacytoid dendritic cell. Red lines indicate inhibition in the presence of these blocking monoclonal antibodies; double arrow lines depict interactions.

blockade dependent on $\mathrm{NK}$ and $\mathrm{T}$ effector cells. In addition, PD-1 inhibitor enhances production of INF- $\gamma$ and granzyme B from NK cells against MM cells. Treatment with lenalidomide further upregulates PD-1 inhibitor's enhancement of NK-cell lysis of MM cells (150).

When combined with HDAC6 inhibitor, anti-PD-L1 antibody can trigger even higher MM cell killing mediated by NK and cytotoxic $\mathrm{T}$ cells, compared with killing in the presence of either agent alone (148). In addition, oncolytic reovirus enhances expression of PD-L1 on MM cells and augments the anti-MM effect of anti-PD-L1 inhibitor (147). Furthermore, since T-cell dependent bispecific antibody (TDB) induces the expression of PD-1 on CD8+ T cells following the engagement of T cells and target MM cells, treatment with PD-L1 inhibitor could enhance anti-MM activity of MM targeted TDB, as recently shown using an anti-FcRH5/CD3 TDB (151).

\section{Clinical Studies}

In a phase $1 \mathrm{~b}$ study, monotherapy with PD-1 inhibitor nivolumab was administered in RRMM patients (152); however, no obvious disease regression was observed. The preliminary data from a phase 1 study, which investigated anti-PD1 antibody pembrolizumab in combination with lenalidomide and lowdose dexamethasone in patients with RRMM showed high response rate (76\%) (153). Another phase 2 trial combining pembrolizumab, pomalidomide, and dexamethasone in RRMM patient also showed high response rate (60\%) (154). This study further showed that higher PD-L1 expression on MM is linked to better progression-free survival. Importantly, however, there were more deaths in phase III trials in the cohorts comparing lenalidomide or pomalidomide with dexamethasone together with pembrolizumab than in patients treated with lenalidomide or pomalidomide with dexamethasone, which has curtailed the development of IMiD pembrolizumab combinations.

Regarding clinical trials of PD-L1 antibodies, single agent durvalumab or the combination of durvalumab with lenalidomide (NCT02685826) is being evaluated in patients with newly diagnosed MM. Durvalumab, alone or combined with pomalidomide (NCT02616640); as well as durvalumab in combination with daratumumab or in combination with pomalidomide, dexamethasone, and daratumumab (NCT02807454) are also clinical trials in RRMM patients. However, these trials are currently not actively recruiting patients for the time being due to the abovementioned safety concern. Nonetheless clinical trials of another anti-PD-L1 antibody, atezolizumab are ongoing in patients with RRMM (NCT02431208).

In addition to direct blockade of PD-1/PD-L1 by PD-1 or PD-L1 inhibitor, novel therapeutic interventions, which modulate the expression of PD-L1 on MM cells are under clinical evaluation in RRMM patients, including the combination of oncolytic reovirus with lenalidomide or pomalidomide (NCT03015922), or oncolytic reovirus with bortezomib and dexamethasone (NCT02514382). Moreover, HDAC6 or MEK inhibitors are also under clinical investigation to potentially modulate expression pattern of PD-1 and PD-L1. The studies of PD-L1 inhibitors or PD-L1 modulators are listed in Table 1. 
TABLE 1 | Summary of trials of programmed cell death ligand 1 (PD-L1) inhibitors and treatment, which modulates PD-L1 expression.

\begin{tabular}{|c|c|c|}
\hline Agents & $\begin{array}{l}\text { Effect on PD-L1 in multiple } \\
\text { myeloma (MM) cells }\end{array}$ & Clinical trials in $\mathrm{MM}$ \\
\hline Atezolizumab & Direct inhibition & $\begin{array}{l}\text { 1. Alone or in combination with an IMiD and/or daratumumab in relapse and refractory MM (RRMM) } \\
\text { patients, phase } 1 \text { (NCT02431208). Status: recruiting }\end{array}$ \\
\hline Durvalumab & Direct inhibition & $\begin{array}{l}\text { 1. Monotherapy or in combination with pomalidomide with or without dexamethasone in RRMM } \\
\text { patients, phase } 1 \text { (NCT02616640). Status: active, not recruiting } \\
\text { 2. Combination of durvalumab with lenalidomide with or without dexamethasone in newly diagnosed } \\
\text { MM patients, phase } 1 \text { (NCT02685826). Status: active, not recruiting } \\
\text { 3. Combination of durvalumab with daratumumab with or without pomalidomide and dexamethasone } \\
\text { in RRMM patients, phase } 2 \text { (NCT02807454). Status: active, not recruiting }\end{array}$ \\
\hline Proteasome inhibitor & Upregulation & $\begin{array}{l}\text { 1. Bortezomib with oncolytic reovirus and dexamethasone in RRMM patients (NCT02514382). Status: } \\
\text { recruiting }\end{array}$ \\
\hline Oncolytic reovirus & Upregulation & $\begin{array}{l}\text { 1. Bortezomib with oncolytic reovirus and dexamethasone in RRMM patients (NCT02514382). Status: } \\
\text { recruiting } \\
\text { 2. Combined with lenalidomide or pomalidomide in RRMM patients, phase 1 (NCT03015922). Status: } \\
\text { recruiting }\end{array}$ \\
\hline HDAC6 inhibitors & Upregulation in MM cells & $\begin{array}{l}\text { Ricolinostat (ACY-241): } \\
\text { 1. Combination with pomalidomide and dexamethasone in RRMM patients, phase 1b/2 } \\
\text { (NCT01997840). Status: active, not recruiting }\end{array}$ \\
\hline MEK1/2 inhibitor & Downregulation & $\begin{array}{l}\text { 1. Binimetinib with encorafenib in RRMM patients with BRAFV600 E or BRAFV600K mutation, phase } \\
2 \text { (NCT02834364). Status: recruiting }\end{array}$ \\
\hline BTK inhibitor & Downregulation & $\begin{array}{l}\text { 1. Ibrutinib with carfilzomib and dexamethasone in RRMM patients, phase 1/2 (NCT01962792). } \\
\text { Status: active, not recruiting } \\
\text { 2. Ibrutinib with pomalidomide, and dexamethasone in RRMM patients: phase 1/2 (NCT02548962). } \\
\text { Status: active, not recruiting } \\
\text { 3. Ibrutinib, bortezomib, and dexamethasone in RRMM patients, phase } 2 \text { (NCTO2902965). Status: } \\
\text { active, not recruiting }\end{array}$ \\
\hline $\begin{array}{l}\text { A proliferation-inducing } \\
\text { ligand (APRIL) inhibitor }\end{array}$ & Downregulation & BION-1301 in RRMM patients, phase $1 / 2$ (NCT03340883). Status: recruiting \\
\hline APRIL CAR T cells & Downregulation & RRMM patients, phase 1/2 (NCT03287804). Status: recruiting \\
\hline BCMA CAR T cells & Downregulation & $\begin{array}{l}\text { 1. bb2121 in RRMM patients, phase } 1 \text { (NCT02658929). Status: active, not recruiting. } \\
\text { 2. bb2121 in RRMM patients, phase } 2 \text { (NCT03361748). Status: recruiting. } \\
\text { 3. Anti-BCMA CAR-T for heavily pretreated MM patients, phase } 1 \text { (NCT02215967). Status: active, not } \\
\text { recruiting. } \\
\text { 4. Combination of anti-BCMA CAR-T with lenalidomide in RRMM patients, phase } 1 \text { (NCT03070327). } \\
\text { Status: recruiting. }\end{array}$ \\
\hline
\end{tabular}

\section{THERAPEUTIC INTERVENTIONS TARGETING OCs IN MM THERAPIES}

Many novel agents have been under evaluation not only for their direct anti-MM activity but also their abilities to abrogate MM-supporting activities in the BM microenvironment, including targeting of OCs. They include bortezomib and IMiDs, which are already standard anti-MM therapies, as well as several novel agents showing promising results in preclinical studies (Table 2).

Bortezomib, as a proteasome inhibitor, not only has direct anti-MM activity, but also targets cells associated with MM bone disease. Bortezomib induces dose-dependent growth inhibition and apoptosis, as well as blocks differentiation, of OCs. It further decreases the resorption capacity of mature OCs, reduces the total number of functional OCs, and increases differentiation of OBs (155-157). In addition to the induction of differentiation and growth of OBs, therapeutic proteasome inhibitors bortezomib and carfilzomib promote bone nodule formation, associated with reduced levels of DKK-1 and RANKL (158-160). Bortezomib preferentially induces differentiation of mesenchymal stem/ progenitor cells to OBs by regulating expression of the bonespecifying transcription factor runt-related transcription factor 2 in a mouse model (161).

Immunomodulatory drugs inhibit formation of OCs by inhibiting PU.1 and pERK $(2,162)$. Cathepsin K, an important molecule in bone collagen matrix resorption, and the serum level of RANKL and RANKL/OPG ratio are significantly reduced in MM patients receiving lenalidomide treatment. Furthermore, lenalidomide and pomalidomide normalize RANKL/OPG ratio and inhibit upregulation of RANKL by downregulating adhesion molecules on MM cells (163).

Bisphosphonate is routinely used in MM bone disease treatment to reduce risk of skeletal events $(164,165)$. Bisphosphonate has high affinity for bone mineral surfaces at sites of active bone remodeling by OCs. It induces apoptosis of OCs while protecting OBs from apoptosis, in addition to blocking differentiation and maturation of OCs $(2,166,167)$. 
TABLE 2 | Summary of therapeutic agents targeting osteoclasts (OCs) and other cells associated with multiple myeloma bone disease.

\begin{tabular}{|c|c|c|}
\hline Agents & Mechanisms & Reference \\
\hline Proteasome inhibitor & $\begin{array}{l}\text { 1. Induce apoptosis and block differentiation of OCs } \\
\text { 2. Increase differentiation of OB } \\
\text { 3. Reduced level of DKK-1 and receptor activator of nuclear factor- } \mathrm{B} B(N F-\kappa B) \text { ligand (RANKL) }\end{array}$ & $\begin{array}{l}(94,155,157 \\
159,160)\end{array}$ \\
\hline Immunomodulatory drugs & $\begin{array}{l}\text { 1. Targeting PU.1 and pERK to inhibit formation of OC } \\
\text { 2. Normalize RANKL/osteoprotegerin ratio }\end{array}$ & $(162,163)$ \\
\hline Bisphosphonate & $\begin{array}{l}\text { 1. Induce } O C \text { apoptosis but protect } O B \text { from apoptosis } \\
\text { 2. Block differentiation and maturation of } O C\end{array}$ & $(166,167)$ \\
\hline RANKL inhibitor & $\begin{array}{l}\text { 1. Decrease OC formation and activity. } \\
\text { 2. Minimal or stimulatory effects on OB. }\end{array}$ & $(18,168,169)$ \\
\hline BTK inhibitor & $\begin{array}{l}\text { 1. Suppress bone resorption and differentiation of OCs } \\
\text { 2. Inhibit secretion of multiple cytokines and chemokines from OCs and bone marrow stromal cells }\end{array}$ & $(93,94)$ \\
\hline Anti-CD38 antibody & $\begin{array}{l}\text { 1. Inhibition of OC formation and bone resorption } \\
\text { 2. Overcome the inhibition of T-cell proliferation blocked by OCs } \\
\text { 3. Inhibit immune checkpoint molecules on OCs }\end{array}$ & $(20,173)$ \\
\hline $\begin{array}{l}\text { Programmed cell death protein 1/programmed } \\
\text { cell death ligand } 1 \text { antibody }\end{array}$ & Block OC-mediated inhibition in T-cell activation and proliferation & $(20)$ \\
\hline
\end{tabular}

Denosumab (AMG165), a fully human monoclonal antibody (IgG2), blocks the binding of RANKL to its receptor expressed on OCs and their precursors, leading to decreased OC activity and inhibition of bone resorption, followed by increased bone mass and strength $(168,169)$. Denosumab reduces bone resorption, increases mass of cortical and cancellous bone, and improves the microstructure of trabecular bone (170). A phase 3 clinical trial in MM has shown that denosumab is not inferior to zoledronic acid, the bisphosphonate most commonly used to reduce skeletal-related event in newly diagnosed MM patients $(3,171)$.

The development and integration of anti-CD38 monoclonal antibody is an important milestone in MM immunotherapy. In addition to MM cells, CD 38 is also expressed on normal PCs, NK cells, monocytes, early OC progenitors, and OCs, but not on the surface of stromal and osteoblastic cells $(172,173)$. Daratumumab inhibits OC formation and bone resorption (173). The inhibition of T-cell proliferation caused by OCs is partially overcome by anti-CD38 monoclonal antibody isatuximab (20) via inhibition of multiple immune checkpoint molecules expressed on OC. Since anti-PD-L1 partially overcomes inhibitory effects of OCs on T-cell activation and proliferation, these results suggest potential therapeutic benefit of combining CD38 and $\mathrm{PD}-1 / \mathrm{PD}-\mathrm{L} 1 \mathrm{mAbs}$ to block OC-induced immunosuppression in MM.

\section{PERSPECTIVES AND CONCLUSION}

Programmed cell death protein 1/PD-L1 pathway plays a critical role in the immunosuppressive tumor microenvironment in MM. As PD-L1 is overexpressed in MM patient cells and other cells associated with immunosuppression including OCs, MDSCs, TAMs, Tregs, and pDCs, blockade of PD-1/PD-L1 pathway may confer an anti-MM effect by restoring the immune dysfunction. Early phase clinical trials in MM showed that blockade of PD-1/ PD-L1 pathway alone does not achieve responses. Although combining PD-1 inhibitor with IMiDs (lenalidomide and pomalidomide) showed higher response rates in RRMM patients, clinical trials combining PD-1 inhibitors with IMiDs in MM are currently put on hold due to safety concerns.

On the other hand, anti-PD-L1 mAbs also show promising clinical benefit with acceptable safety profile in clinical trials of various solid tumors, leading to increasing interest in targeting PD-L1 in MM (174). Preclinical studies showed that treatment with anti-PD-L1 antibody induces no direct MM killing, but significantly restores the anti-MM activity of cytotoxic $\mathrm{T}$ cells or NK cells, suggesting that PD-L1 inhibitor might be a therapeutic partner with other anti-MM agents. Several combinations of molecules which either upregulate or downregulate expression of PD-L1 in combination with anti-MM agents are under evaluation (Table 1). Early phase clinical trials conducted with BCMA CAR-T therapy, HDAC6 inhibitors, and oncolytic reovirus in RRMM patients have shown preliminary promising results (175-177). Novel strategies targeting immune checkpoints and the OC-related pathway have also shown impressive results in preclinical studies. For example, the combination of RANKL and CTLA4 antibody enhances antitumor effect of lymphocytes (178). Blockade of RANKL pathway also augments the antitumor effect of PD1-PD-L1 blockade or dual PD1-PD-L1 and CTLA4 blockade in an animal model (179). Since RANKL inhibitor is now used in MM patients with bone disease, combinations with above agent represent potential novel therapeutic strategies. Finally, preclinical data combining CD38 with PD-1 and/ or PD-L1 mAbs provides the rationale for clinical evaluation of these combinations. These various combination therapies may overcome primary and acquired resistance to anti-PD-1/PD-L1 therapies in MM.

An effective anti-MM immunotherapy not only relies on effective killing of MM cells themselves, but also on successfully restoring anticancer immune function. Immunotherapy targeting PD-1/PD-L1 pathway has revolutionized the treatment in several progressive solid tumors but is accompanied by 
immune-related adverse events in some patients. For anti-PD-1/ PD-L1 immunotherapy to proceed in MM, it will be critical to investigate both the direct effects on tumor cells, as well as the impact on cellular- and cytokine-mediated immunosuppression in the MM microenvironment. Moreover, delineating molecular mechanisms regulating PD-L1 and PD-1 expression in the MM BM milieu will identify novel targets for potential therapeutic application.

\section{AUTHOR CONTRIBUTIONS}

Y-TT and S-FC review literatures and design and write this paper. Y-TT and KA critically review and edit the paper.

\section{REFERENCES}

1. Palumbo A, Anderson K. Multiple myeloma. N Engl J Med (2011) 364(11): 1046-60. doi:10.1056/NEJMra1011442

2. Raje N, Roodman GD. Advances in the biology and treatment of bone disease in multiple myeloma. Clin Cancer Res (2011) 17(6):1278-86. doi:10.1158/1078-0432.CCR-10-1804

3. Anderson K, Ismaila N, Flynn PJ, Halabi S, Jagannath S, Ogaily MS, et al. Role of bone-modifying agents in multiple myeloma: American Society of Clinical Oncology Clinical Practice Guideline Update. J Clin Oncol (2018) 36(8):812-8. doi:10.1200/JCO.2017.76.6402

4. Rajkumar SV, Blood E, Vesole D, Fonseca R, Greipp PR; Eastern Cooperative Oncology G. Phase III clinical trial of thalidomide plus dexamethasone compared with dexamethasone alone in newly diagnosed multiple myeloma: a clinical trial coordinated by the Eastern Cooperative Oncology Group. J Clin Oncol (2006) 24(3):431-6. doi:10.1200/JCO.2005.03.0221

5. San Miguel JF, Schlag R, Khuageva NK, Dimopoulos MA, Shpilberg O, Kropff $\mathrm{M}$, et al. Bortezomib plus melphalan and prednisone for initial treatment of multiple myeloma. N Engl J Med (2008) 359(9):906-17. doi:10.1056/ NEJMoa0801479

6. Richardson PG, Weller E, Lonial S, Jakubowiak AJ, Jagannath S, Raje NS, et al. Lenalidomide, bortezomib, and dexamethasone combination therapy in patients with newly diagnosed multiple myeloma. Blood (2010) 116(5): 679-86. doi:10.1182/blood-2010-02-268862

7. Benboubker L, Dimopoulos MA, Dispenzieri A, Catalano J, Belch AR, Cavo M, et al. Lenalidomide and dexamethasone in transplant-ineligible patients with myeloma. N Engl J Med (2014) 371(10):906-17. doi:10.1056/ NEJMoa1402551

8. Kumar SK, Anderson KC. Immune therapies in multiple myeloma. Clin Cancer Res (2016) 22(22):5453-60. doi:10.1158/1078-0432.CCR-16-0868

9. Mateos MV, Dimopoulos MA, Cavo M, Suzuki K, Jakubowiak A, Knop S, et al. Daratumumab plus bortezomib, melphalan, and prednisone for untreated myeloma. N Engl J Med (2018) 378(6):518-28. doi:10.1056/NEJMoa1714678

10. Jiang H, Acharya C, An G, Zhong M, Feng X, Wang L, et al. SAR650984 directly induces multiple myeloma cell death via lysosomal-associated and apoptotic pathways, which is further enhanced by pomalidomide. Leukemia (2016) 30(2):399-408. doi:10.1038/leu.2015.240

11. Martin T, Baz R, Benson DM, Lendvai N, Wolf J, Munster P, et al. A phase $1 \mathrm{~b}$ study of isatuximab plus lenalidomide and dexamethasone for relapsed/ refractory multiple myeloma. Blood (2017) 129(25):3294-303. doi:10.1182/ blood-2016-09-740787

12. Richardson PG, Attal M, Campana F, Le-Guennec S, Hui AM, Risse ML, et al. Isatuximab plus pomalidomide/dexamethasone versus pomalidomide/dexamethasone in relapsed/refractory multiple myeloma: ICARIA phase III study design. Future Oncol (2018) 14(11):1035-47. doi:10.2217/fon-2017-0616

13. Hideshima T, Anderson KC. Molecular mechanisms of novel therapeutic approaches for multiple myeloma. Nat Rev Cancer (2002) 2(12):927-37. doi:10.1038/nrc952

14. Kawano Y, Moschetta M, Manier S, Glavey S, Gorgun GT, Roccaro AM, et al. Targeting the bone marrow microenvironment in multiple myeloma. Immunol Rev (2015) 263(1):160-72. doi:10.1111/imr.12233

\section{ACKNOWLEDGMENTS}

We thank all laboratory and clinical research teams at the LeBow Institute for Myeloma Therapeutics and the Jerome Lipper Multiple Myeloma Center of the Dana-Farber Cancer Institute for their continuous encouragement, help, and support.

\section{FUNDING}

This work was supported in part by grants from the National Institutes of Health Grants P50-100007, and PO1-155258 and RO1-50947. KA is an American Cancer Society Clinical Research Professor.

15. Fowler JA, Mundy GR, Lwin ST, Edwards CM. Bone marrow stromal cells create a permissive microenvironment for myeloma development: a new stromal role for Wnt inhibitor Dkk1. Cancer Res (2012) 72(9):2183-9. doi:10.1158/0008-5472.CAN-11-2067

16. Roodman GD. Mechanisms of bone metastasis. N Engl J Med (2004) 350(16):1655-64. doi:10.1056/NEJMra030831

17. Tai YT, Fulciniti M, Hideshima T, Song W, Leiba M, Li XF, et al. Targeting MEK induces myeloma-cell cytotoxicity and inhibits osteoclastogenesis. Blood (2007) 110(5):1656-63. doi:10.1182/blood-2007-03-081240

18. Tai YT, Landesman Y, Acharya C, Calle Y, Zhong MY, Cea M, et al. CRM1 inhibition induces tumor cell cytotoxicity and impairs osteoclastogenesis in multiple myeloma: molecular mechanisms and therapeutic implications. Leukemia (2014) 28(1):155-65. doi:10.1038/leu.2013.115

19. Raje N, Woo SB, Hande K, Yap JT, Richardson PG, Vallet S, et al. Clinical, radiographic, and biochemical characterization of multiple myeloma patients with osteonecrosis of the jaw. Clin Cancer Res (2008) 14(8):2387-95. doi:10.1158/1078-0432.CCR-07-1430

20. An G, Acharya C, Feng X, Wen K, Zhong M, Zhang L, et al. Osteoclasts promote immune suppressive microenvironment in multiple myeloma: therapeutic implication. Blood (2016) 128(12):1590-603. doi:10.1182/blood2016-03-707547

21. Brimnes MK, Vangsted AJ, Knudsen LM, Gimsing P, Gang AO, Johnsen HE, et al. Increased level of both CD4+FOXP3+ regulatory $\mathrm{T}$ cells and CD14+HLA-DR(-)/low myeloid-derived suppressor cells and decreased level of dendritic cells in patients with multiple myeloma. Scand J Immunol (2010) 72(6):540-7. doi:10.1111/j.1365-3083.2010.02463.x

22. Gorgun GT, Whitehill G, Anderson JL, Hideshima T, Maguire C, Laubach J, et al. Tumor-promoting immune-suppressive myeloid-derived suppressor cells in the multiple myeloma microenvironment in humans. Blood (2013) 121(15):2975-87. doi:10.1182/blood-2012-08-448548

23. De Beule N, De Veirman K, Maes K, De Bruyne E, Menu E, Breckpot K, et al. Tumour-associated macrophage-mediated survival of myeloma cells through STAT3 activation. J Pathol (2017) 241(4):534-46. doi:10.1002/ path. 4860

24. Braga WM, da Silva BR, de Carvalho AC, Maekawa YH, Bortoluzzo AB, Rizzatti EG, et al. FOXP3 and CTLA4 overexpression in multiple myeloma bone marrow as a sign of accumulation of $\mathrm{CD} 4(+) \mathrm{T}$ regulatory cells. Cancer Immunol Immunother (2014) 63(11):1189-97. doi:10.1007/s00262014-1589-9

25. Feng X, Zhang L, Acharya C, An G, Wen K, Qiu L, et al. Targeting CD38 suppresses induction and function of $\mathrm{T}$ regulatory cells to mitigate immunosuppression in multiple myeloma. Clin Cancer Res (2017) 23(15):4290-300. doi:10.1158/1078-0432.CCR-16-3192

26. Chauhan D, Singh AV, Brahmandam M, Carrasco R, Bandi M, Hideshima T, et al. Functional interaction of plasmacytoid dendritic cells with multiple myeloma cells: a therapeutic target. Cancer Cell (2009) 16(4):309-23. doi:10.1016/j.ccr.2009.08.019

27. Zhang L, Tai YT, Ho M, Xing L, Chauhan D, Gang A, et al. Regulatory B cell-myeloma cell interaction confers immunosuppression and promotes their survival in the bone marrow milieu. Blood Cancer J (2017) 7(3):e547. doi:10.1038/bcj.2017.24 
28. Roodman GD. Role of the bone marrow microenvironment in multiple myeloma. J Bone Miner Res (2002) 17(11):1921-5. doi:10.1359/jbmr.2002. 17.11.1921

29. Tai YT, Dillon M, Song W, Leiba M, Li XF, Burger P, et al. Anti-CS1 humanized monoclonal antibody HuLuc63 inhibits myeloma cell adhesion and induces antibody-dependent cellular cytotoxicity in the bone marrow milieu. Blood (2008) 112(4):1329-37. doi:10.1182/blood-2007-08-107292

30. Kollet O, Dar A, Shivtiel S, Kalinkovich A, Lapid K, Sztainberg Y, et al. Osteoclasts degrade endosteal components and promote mobilization of hematopoietic progenitor cells. Nat Med (2006) 12(6):657-64. doi:10.1038/ nm1417

31. Mansour A, Abou-Ezzi G, Sitnicka E, Jacobsen SE, Wakkach A, BlinWakkach C. Osteoclasts promote the formation of hematopoietic stem cell niches in the bone marrow. J Exp Med (2012) 209(3):537-49. doi:10.1084/ jem.20110994

32. Lawson MA, McDonald MM, Kovacic N, Hua Khoo W, Terry RL, Down J, et al. Osteoclasts control reactivation of dormant myeloma cells by remodelling the endosteal niche. Nat Commun (2015) 6:8983. doi:10.1038/ ncomms 9983

33. Takayanagi H. Osteoimmunology: shared mechanisms and crosstalk between the immune and bone systems. Nat Rev Immunol (2007) 7(4):292-304. doi:10.1038/nri2062

34. Lorenzo J, Horowitz M, Choi Y. Osteoimmunology: interactions of the bone and immune system. Endocr Rev (2008) 29(4):403-40. doi:10.1210/ er.2007-0038

35. Charles JF, Nakamura MC. Bone and the innate immune system. Curr Osteoporos Rep (2014) 12(1):1-8. doi:10.1007/s11914-014-0195-2

36. Dong H, Zhu G, Tamada K, Chen L. B7-H1, a third member of the B7 family, co-stimulates T-cell proliferation and interleukin-10 secretion. Nat Med (1999) 5(12):1365-9. doi:10.1038/70932

37. Chen L, Han X. Anti-PD-1/PD-L1 therapy of human cancer: past, present, and future. J Clin Invest (2015) 125(9):3384-91. doi:10.1172/JCI80011

38. Nurieva R, Thomas S, Nguyen T, Martin-Orozco N, Wang Y, Kaja MK, et al. T-cell tolerance or function is determined by combinatorial costimulatory signals. EMBO J (2006) 25(11):2623-33. doi:10.1038/sj.emboj.7601146

39. Freeman GJ, Long AJ, Iwai $Y$, Bourque $K$, Chernova T, Nishimura $H$, et al. Engagement of the PD-1 immunoinhibitory receptor by a novel B7 family member leads to negative regulation of lymphocyte activation. J Exp Med (2000) 192(7):1027-34. doi:10.1084/jem.192.7.1027

40. Riley JL. PD-1 signaling in primary T cells. Immunol Rev (2009) 229(1): 114-25. doi:10.1111/j.1600-065X.2009.00767.x

41. Chen DS, Irving BA, Hodi FS. Molecular pathways: next-generation immunotherapy - inhibiting programmed death-ligand 1 and programmed death-1. Clin Cancer Res (2012) 18(24):6580-7. doi:10.1158/1078-0432. CCR-12-1362

42. Sun Z, Fourcade J, Pagliano O, Chauvin JM, Sander C, Kirkwood JM, et al. IL10 and PD-1 cooperate to limit the activity of tumor-specific CD8+ T cells. Cancer Res (2015) 75(8):1635-44. doi:10.1158/0008-5472.CAN14-3016

43. Butte MJ, Keir ME, Phamduy TB, Sharpe AH, Freeman GJ. Programmed death-1 ligand 1 interacts specifically with the B7-1 costimulatory molecule to inhibit T cell responses. Immunity (2007) 27(1):111-22. doi:10.1016/j. immuni.2007.05.016

44. Ansari MJ, Salama AD, Chitnis T, Smith RN, Yagita H, Akiba H, et al. The programmed death-1 (PD-1) pathway regulates autoimmune diabetes in nonobese diabetic (NOD) mice. J Exp Med (2003) 198(1):63-9. doi:10.1084/ jem.20022125

45. Francisco LM, Sage PT, Sharpe AH. The PD-1 pathway in tolerance and autoimmunity. Immunol Rev (2010) 236:219-42. doi:10.1111/j.1600-065X. 2010.00923.x

46. Lazar-Molnar E, Gacser A, Freeman GJ, Almo SC, Nathenson SG, Nosanchuk JD. The PD-1/PD-L costimulatory pathway critically affects host resistance to the pathogenic fungus Histoplasma capsulatum. Proc Natl Acad Sci U S A (2008) 105(7):2658-63. doi:10.1073/pnas.0711918105

47. Wu P, Wu D, Li L, Chai Y, Huang J. PD-L1 and survival in solid tumors: a meta-analysis. PLoS One (2015) 10(6):e0131403. doi:10.1371/journal.pone. 0131403

48. Hamanishi J, Mandai M, Iwasaki M, Okazaki T, Tanaka Y, Yamaguchi K, et al. Programmed cell death 1 ligand 1 and tumor-infiltrating CD8+
T lymphocytes are prognostic factors of human ovarian cancer. Proc Natl Acad Sci U S A (2007) 104(9):3360-5. doi:10.1073/pnas.0611533104

49. Huang B, Chen L, Bao C, Sun C, Li J, Wang L, et al. The expression status and prognostic significance of programmed cell death 1 ligand 1 in gastrointestinal tract cancer: a systematic review and meta-analysis. Onco Targets Ther (2015) 8:2617-25. doi:10.2147/OTT.S91025

50. Errico A. Immunotherapy: PD-1-PD-L1 axis: efficient checkpoint blockade against cancer. Nat Rev Clin Oncol (2015) 12(2):63. doi:10.1038/nrclinonc. 2014.221

51. Pianko MJ, Moskowitz AJ, Lesokhin AM. Immunotherapy of lymphoma and myeloma: facts and hopes. Clin Cancer Res (2018) 24(5):1002-10. doi:10.1158/1078-0432.CCR-17-0539

52. Xu-Monette ZY, Zhou J, Young KH. PD-1 expression and clinical PD-1 blockade in B-cell lymphomas. Blood (2018) 131(1):68-83. doi:10.1182/ blood-2017-07-740993

53. Ishibashi M, Tamura H, Sunakawa M, Kondo-Onodera A, Okuyama N, Hamada $\mathrm{Y}$, et al. Myeloma drug resistance induced by binding of myeloma B7-H1 (PD-L1) to PD-1. Cancer Immunol Res (2016) 4(9):779-88. doi:10.1158/2326-6066.CIR-15-0296

54. Kearl TJ, Jing W, Gershan JA, Johnson BD. Programmed death receptor-1/ programmed death receptor ligand-1 blockade after transient lymphodepletion to treat myeloma. J Immunol (2013) 190(11):5620-8. doi:10.4049/ jimmunol.1202005

55. Rosenblatt J, Avigan D. Targeting the PD-1/PD-L1 axis in multiple myeloma: a dream or a reality? Blood (2017) 129(3):275-9. doi:10.1182/ blood-2016-08-731885

56. Teitelbaum SL. Bone resorption by osteoclasts. Science (2000) 289(5484):1504-8. doi:10.1126/science.289.5484.1504

57. Bataille R, Chappard D, Marcelli C, Dessauw P, Sany J, Baldet P, et al. Mechanisms of bone destruction in multiple myeloma: the importance of an unbalanced process in determining the severity of lytic bone disease. J Clin Oncol (1989) 7(12):1909-14. doi:10.1200/JCO.1989.7.12.1909

58. Dimopoulos MA, Moulopoulos LA, Datseris I, Weber D, Delasalle K, Gika D, et al. Imaging of myeloma bone disease - implications for staging, prognosis and follow-up. Acta Oncol (2000) 39(7):823-7. doi:10.1080/ 028418600750063578

59. Dimopoulos M, Terpos E, Comenzo RL, Tosi P, Beksac M, Sezer O, et al. International myeloma working group consensus statement and guidelines regarding the current role of imaging techniques in the diagnosis and monitoring of multiple myeloma. Leukemia (2009) 23(9):1545-56. doi:10.1038/ leu.2009.89

60. Kyle RA. Multiple myeloma: review of 869 cases. Mayo Clin Proc (1975) 50(1):29-40.

61. Sonmez M, Akagun T, Topbas M, Cobanoglu U, Sonmez B, Yilmaz M, et al. Effect of pathologic fractures on survival in multiple myeloma patients: a case control study. J Exp Clin Cancer Res (2008) 27:11. doi:10.1186/17569966-27-11

62. D'Souza S, del Prete D, Jin S, Sun Q, Huston AJ, Kostov FE, et al. Gfil expressed in bone marrow stromal cells is a novel osteoblast suppressor in patients with multiple myeloma bone disease. Blood (2011) 118(26):6871-80. doi:10.1182/blood-2011-04-346775

63. Sanz-Rodriguez F, Hidalgo A, Teixido J. Chemokine stromal cell-derived factor-1alpha modulates VLA-4 integrin-mediated multiple myeloma cell adhesion to CS-1/fibronectin and VCAM-1. Blood (2001) 97(2):346-51. doi:10.1182/blood.V97.2.346

64. Gunn WG, Conley A, Deininger L, Olson SD, Prockop DJ, Gregory CA. A crosstalk between myeloma cells and marrow stromal cells stimulates production of DKK1 and interleukin-6: a potential role in the development of lytic bone disease and tumor progression in multiple myeloma. Stem Cells (2006) 24(4):986-91. doi:10.1634/stemcells.2005-0220

65. Giuliani N, Colla S, Rizzoli V. New insight in the mechanism of osteoclast activation and formation in multiple myeloma: focus on the receptor activator of NF-kappaB ligand (RANKL). Exp Hematol (2004) 32(8):685-91. doi:10.1016/j.exphem.2004.03.015

66. Choi SJ, Cruz JC, Craig F, Chung H, Devlin RD, Roodman GD, et al. Macrophage inflammatory protein 1-alpha is a potential osteoclast stimulatory factor in multiple myeloma. Blood (2000) 96(2):671-5.

67. Lee JW, Chung HY, Ehrlich LA, Jelinek DF, Callander NS, Roodman GD, et al. IL-3 expression by myeloma cells increases both osteoclast formation 
and growth of myeloma cells. Blood (2004) 103(6):2308-15. doi:10.1182/ blood-2003-06-1992

68. Uchiyama H, Barut BA, Mohrbacher AF, Chauhan D, Anderson KC. Adhesion of human myeloma-derived cell lines to bone marrow stromal cells stimulates interleukin-6 secretion. Blood (1993) 82(12):3712-20.

69. Zannettino AC, Farrugia AN, Kortesidis A, Manavis J, To LB, Martin SK, et al. Elevated serum levels of stromal-derived factor-1alpha are associated with increased osteoclast activity and osteolytic bone disease in multiple myeloma patients. Cancer Res (2005) 65(5):1700-9. doi:10.1158/0008-5472. CAN-04-1687

70. Colucci S, Brunetti G, Rizzi R, Zonno A, Mori G, Colaianni G, et al. T cells support osteoclastogenesis in an in vitro model derived from human multiple myeloma bone disease: the role of the OPG/TRAIL interaction. Blood (2004) 104(12):3722-30. doi:10.1182/blood-2004-02-0474

71. Tai YT, Li XF, Breitkreutz I, Song W, Neri P, Catley L, et al. Role of B-cellactivating factor in adhesion and growth of human multiple myeloma cells in the bone marrow microenvironment. Cancer Res (2006) 66(13):6675-82. doi:10.1158/0008-5472.CAN-06-0190

72. Hemingway F, Taylor R, Knowles HJ, Athanasou NA. RANKL-independent human osteoclast formation with APRIL, BAFF, NGF, IGF I and IGF II. Bone (2011) 48(4):938-44. doi:10.1016/j.bone.2010.12.023

73. Nguyen AN, Stebbins EG, Henson M, O’Young G, Choi SJ, Quon D, et al. Normalizing the bone marrow microenvironment with p38 inhibitor reduces multiple myeloma cell proliferation and adhesion and suppresses osteoclast formation. Exp Cell Res (2006) 312(10):1909-23. doi:10.1016/j. yexcr.2006.02.026

74. Fu J, Li S, Feng R, Ma H, Sabeh F, Roodman GD, et al. Multiple myelomaderived MMP-13 mediates osteoclast fusogenesis and osteolytic disease. J Clin Invest (2016) 126(5):1759-72. doi:10.1172/JCI80276

75. Abe M, Hiura K, Wilde J, Shioyasono A, Moriyama K, Hashimoto T, et al. Osteoclasts enhance myeloma cell growth and survival via cell-cell contact: a vicious cycle between bone destruction and myeloma expansion. Blood (2004) 104(8):2484-91. doi:10.1182/blood-2003-11-3839

76. Moreaux J, Cremer FW, Reme T, Raab M, Mahtouk K, Kaukel P, et al. The level of TACI gene expression in myeloma cells is associated with a signature of microenvironment dependence versus a plasmablastic signature. Blood (2005) 106(3):1021-30. doi:10.1182/blood-2004-11-4512

77. D'Souza S, Kurihara N, Shiozawa Y, Joseph J, Taichman R, Galson DL, et al. Annexin II interactions with the annexin II receptor enhance multiple myeloma cell adhesion and growth in the bone marrow microenvironment. Blood (2012) 119(8):1888-96. doi:10.1182/blood-2011-11-393348

78. Sprynski AC, Hose D, Caillot L, Reme T, Shaughnessy JD Jr, Barlogie B, et al. The role of IGF-1 as a major growth factor for myeloma cell lines and the prognostic relevance of the expression of its receptor. Blood (2009) 113(19):4614-26. doi:10.1182/blood-2008-07-170464

79. Tian E, Zhan F, Walker R, Rasmussen E, Ma Y, Barlogie B, et al. The role of the Wnt-signaling antagonist DKK1 in the development of osteolytic lesions in multiple myeloma. N Engl J Med (2003) 349(26):2483-94. doi:10.1056/ NEJMoa030847

80. Standal T, Abildgaard N, Fagerli UM, Stordal B, Hjertner O, Borset M, et al. HGF inhibits BMP-induced osteoblastogenesis: possible implications for the bone disease of multiple myeloma. Blood (2007) 109(7):3024-30. doi:10.1182/blood-2006-07-034884

81. Jost E, Gezer D, Wilop S, Suzuki H, Herman JG, Osieka R, et al. Epigenetic dysregulation of secreted Frizzled-related proteins in multiple myeloma. Cancer Lett (2009) 281(1):24-31. doi:10.1016/j.canlet.2009.02.002

82. Vallet S, Mukherjee S, Vaghela N, Hideshima T, Fulciniti M, Pozzi S, et al. Activin A promotes multiple myeloma-induced osteolysis and is a promising target for myeloma bone disease. Proc Natl Acad Sci U S A (2010) 107(11):5124-9. doi:10.1073/pnas.0911929107

83. Terpos E, Christoulas D, Katodritou E, Bratengeier C, Gkotzamanidou M, Michalis E, et al. Elevated circulating sclerostin correlates with advanced disease features and abnormal bone remodeling in symptomatic myeloma: reduction post-bortezomib monotherapy. Int J Cancer (2012) 131(6):146671. doi:10.1002/ijc. 27342

84. Giuliani N, Rizzoli V, Roodman GD. Multiple myeloma bone disease: pathophysiology of osteoblast inhibition. Blood (2006) 108(13):3992-6. doi:10.1182/blood-2006-05-026112
85. Pearse RN, Sordillo EM, Yaccoby S, Wong BR, Liau DF, Colman N, et al. Multiple myeloma disrupts the TRANCE/osteoprotegerin cytokine axis to trigger bone destruction and promote tumor progression. Proc Natl Acad Sci U S A (2001) 98(20):11581-6. doi:10.1073/pnas.201394498

86. Jakob C, Goerke A, Terpos E, Sterz J, Heider U, Kuhnhardt D, et al. Serum levels of total-RANKL in multiple myeloma. Clin Lymphoma Myeloma (2009) 9(6):430-5. doi:10.3816/CLM.2009.n.085

87. Farrugia AN, Atkins GJ, To LB, Pan B, Horvath N, Kostakis P, et al. Receptor activator of nuclear factor-kappaB ligand expression by human myeloma cells mediates osteoclast formation in vitro and correlates with bone destruction in vivo. Cancer Res (2003) 63(17):5438-45.

88. Heider U, Langelotz C, Jakob C, Zavrski I, Fleissner C, Eucker J, et al. Expression of receptor activator of nuclear factor kappaB ligand on bone marrow plasma cells correlates with osteolytic bone disease in patients with multiple myeloma. Clin Cancer Res (2003) 9(4):1436-40.

89. Nakashima T, Kobayashi Y, Yamasaki S, Kawakami A, Eguchi K, Sasaki H, et al. Protein expression and functional difference of membrane-bound and soluble receptor activator of NF-kappaB ligand: modulation of the expression by osteotropic factors and cytokines. Biochem Biophys Res Commun (2000) 275(3):768-75. doi:10.1006/bbrc.2000.3379

90. Terpos E, Szydlo R, Apperley JF, Hatjiharissi E, Politou M, Meletis J, et al. Soluble receptor activator of nuclear factor kappaB ligand-osteoprotegerin ratio predicts survival in multiple myeloma: proposal for a novel prognostic index. Blood (2003) 102(3):1064-9. doi:10.1182/blood-2003-02-0380

91. Buckle CH, De Leenheer E, Lawson MA, Yong K, Rabin N, Perry M, et al. Soluble rank ligand produced by myeloma cells causes generalised bone loss in multiple myeloma. PLoS One (2012) 7(8):e41127. doi:10.1371/journal. pone. 0041127

92. Moreaux J, Hose D, Kassambara A, Reme T, Moine P, Requirand G, et al. Osteoclast-gene expression profiling reveals osteoclast-derived CCR2 chemokines promoting myeloma cell migration. Blood (2011) 117(4): 1280-90. doi:10.1182/blood-2010-04-279760

93. Tai YT, Chang BY, Kong SY, Fulciniti M, Yang G, Calle Y, et al. Bruton tyrosine kinase inhibition is a novel therapeutic strategy targeting tumor in the bone marrow microenvironment in multiple myeloma. Blood (2012) 120(9):1877-87. doi:10.1182/blood-2011-12-396853

94. Eda H, Santo L, Cirstea DD, Yee AJ, Scullen TA, Nemani N, et al. A novel Bruton's tyrosine kinase inhibitor CC-292 in combination with the proteasome inhibitor carfilzomib impacts the bone microenvironment in a multiple myeloma model with resultant antimyeloma activity. Leukemia (2014) 28(9):1892-901. doi:10.1038/leu.2014.69

95. Couper KN, Blount DG, Riley EM. IL-10: the master regulator of immunity to infection. JImmunol (2008) 180(9):5771-7. doi:10.4049/ jimmunol.180.9.5771

96. Pittari G, Vago L, Festuccia M, Bonini C, Mudawi D, Giaccone L, et al. Restoring natural killer cell immunity against multiple myeloma in the era of new drugs. Front Immunol (2017) 8:1444. doi:10.3389/fimmu.2017. 01444

97. Brunetti G, Rizzi R, Oranger A, Gigante I, Mori G, Taurino G, et al. LIGHT/ TNFSF14 increases osteoclastogenesis and decreases osteoblastogenesis in multiple myeloma-bone disease. Oncotarget (2014) 5(24):12950-67. doi:10.18632/oncotarget.2633

98. Favaloro J, Brown R, Aklilu E, Yang S, Suen H, Hart D, et al. Myeloma skews regulatory $\mathrm{T}$ and pro-inflammatory $\mathrm{T}$ helper 17 cell balance in favor of a suppressive state. Leuk Lymphoma (2014) 55(5):1090-8. doi:10.3109/10428194. 2013.825905

99. Zhuang J, Zhang J, Lwin ST, Edwards JR, Edwards CM, Mundy GR, et al. Osteoclasts in multiple myeloma are derived from Gr-1+CD11b+myeloidderived suppressor cells. PLoS One (2012) 7(11):e48871. doi:10.1371/journal. pone. 0048871

100. Tucci M, Ciavarella S, Strippoli S, Brunetti O, Dammacco F, Silvestris F. Immature dendritic cells from patients with multiple myeloma are prone to osteoclast differentiation in vitro. Exp Hematol (2011) 39(7):773-83.e1. doi:10.1016/j.exphem.2011.04.006

101. Bolzoni M, Ronchetti D, Storti P, Donofrio G, Marchica V, Costa F, et al. IL21R expressing $\mathrm{CD} 14(+) \mathrm{CD} 16(+)$ monocytes expand in multiple myeloma patients leading to increased osteoclasts. Haematologica (2017) 102(4):773-84. doi:10.3324/haematol.2016.153841 
102. Tanaka Y, Abe M, Hiasa M, Oda A, Amou H, Nakano A, et al. Myeloma cell-osteoclast interaction enhances angiogenesis together with bone resorption: a role for vascular endothelial cell growth factor and osteopontin. Clin Cancer Res (2007) 13(3):816-23. doi:10.1158/1078-0432.CCR-06-2258

103. Cackowski FC, Anderson JL, Patrene KD, Choksi RJ, Shapiro SD, Windle JJ, et al. Osteoclasts are important for bone angiogenesis. Blood (2010) 115(1):140-9. doi:10.1182/blood-2009-08-237628

104. Lee YM, Fujikado N, Manaka H, Yasuda H, Iwakura Y. IL-1 plays an important role in the bone metabolism under physiological conditions. Int Immunol (2010) 22(10):805-16. doi:10.1093/intimm/dxq431

105. Ishimi $\mathrm{Y}$, Miyaura $\mathrm{C}$, Jin $\mathrm{CH}$, Akatsu T, Abe E, Nakamura Y, et al. IL-6 is produced by osteoblasts and induces bone resorption. J Immunol (1990) 145(10):3297-303.

106. Azuma Y, Kaji K, Katogi R, Takeshita S, Kudo A. Tumor necrosis factoralpha induces differentiation of and bone resorption by osteoclasts. J Biol Chem (2000) 275(7):4858-64. doi:10.1074/jbc.275.7.4858

107. Kwan Tat S, Padrines M, Theoleyre S, Heymann D, Fortun Y. IL-6, RANKL, TNF-alpha/IL-1: interrelations in bone resorption pathophysiology. Cytokine Growth Factor Rev (2004) 15(1):49-60. doi:10.1016/j.cytogfr.2003.10.005

108. Karmakar S, Kay J, Gravallese EM. Bone damage in rheumatoid arthritis: mechanistic insights and approaches to prevention. Rheum Dis Clin North Am (2010) 36(2):385-404. doi:10.1016/j.rdc.2010.03.003

109. Kitaura H, Kimura K, Ishida M, Kohara H, Yoshimatsu M, TakanoYamamoto T. Immunological reaction in TNF-alpha-mediated osteoclast formation and bone resorption in vitro and in vivo. Clin Dev Immunol (2013) 2013:181849. doi:10.1155/2013/181849

110. Horwood NJ, Kartsogiannis V, Quinn JM, Romas E, Martin TJ, Gillespie MT. Activated T lymphocytes support osteoclast formation in vitro. Biochem Biophys Res Commun (1999) 265(1):144-50. doi:10.1006/bbrc.1999.1623

111. Choi Y, Woo KM, Ko SH, Lee YJ, Park SJ, Kim HM, et al. Osteoclastogenesis is enhanced by activated B cells but suppressed by activated CD8(+) T cells. Eur J Immunol (2001) 31(7):2179-88. doi:10.1002/1521-4141(200107)31: 7<2179::AID-IMMU2179>3.0.CO;2-X

112. Sato K, Suematsu A, Okamoto K, Yamaguchi A, Morishita Y, Kadono Y, et al. Th17 functions as an osteoclastogenic helper $\mathrm{T}$ cell subset that links T cell activation and bone destruction. J Exp Med (2006) 203(12):2673-82. doi:10.1084/jem.20061775

113. Weitzmann MN, Cenci S, Rifas L, Brown C, Pacifici R. Interleukin-7 stimulates osteoclast formation by up-regulating the T-cell production of soluble osteoclastogenic cytokines. Blood (2000) 96(5):1873-8.

114. Lacey DL, Timms E, Tan HL, Kelley MJ, Dunstan CR, Burgess T, et al. Osteoprotegerin ligand is a cytokine that regulates osteoclast differentiation and activation. Cell (1998) 93(2):165-76. doi:10.1016/S00928674(00)81569-X

115. Giuliani N, Colla S, Sala R, Moroni M, Lazzaretti M, La Monica S, et al. Human myeloma cells stimulate the receptor activator of nuclear factor-kappa B ligand (RANKL) in T lymphocytes: a potential role in multiple myeloma bone disease. Blood (2002) 100(13):4615-21. doi:10.1182/blood-2002-04-1121

116. Takayanagi H, Ogasawara K, Hida S, Chiba T, Murata S, Sato K, et al. $\mathrm{T}$-cell-mediated regulation of osteoclastogenesis by signalling cross-talk between RANKL and IFN-gamma. Nature (2000) 408(6812):600-5. doi: $10.1038 / 35046102$

117. Li H, Hong S, Qian J, Zheng Y, Yang J, Yi Q. Cross talk between the bone and immune systems: osteoclasts function as antigen-presenting cells and activate CD4+ and CD8+ T cells. Blood (2010) 116(2):210-7. doi:10.1182/ blood-2009-11-255026

118. Senthilkumar R, Lee HW. CD137L- and RANKL-mediated reverse signals inhibit osteoclastogenesis and T lymphocyte proliferation. Immunobiology (2009) 214(2):153-61. doi:10.1016/j.imbio.2008.05.001

119. Kiesel JR, Buchwald ZS, Aurora R. Cross-presentation by osteoclasts induces FoxP3 in CD8+ T cells. J Immunol (2009) 182(9):5477-87. doi:10.4049/ jimmunol.0803897

120. Gavin MA, Rasmussen JP, Fontenot JD, Vasta V, Manganiello VC, Beavo JA, et al. Foxp3-dependent programme of regulatory T-cell differentiation. Nature (2007) 445(7129):771-5. doi:10.1038/nature05543

121. Buchwald ZS, Kiesel JR, DiPaolo R, Pagadala MS, Aurora R. Osteoclast activated FoxP3+ CD8+ T-cells suppress bone resorption in vitro. PLoS One (2012) 7(6):e38199. doi:10.1371/journal.pone.0038199
122. Buchwald ZS, Kiesel JR, Yang C, DiPaolo R, Novack DV, Aurora R. Osteoclast-induced Foxp3+ CD8 T-cells limit bone loss in mice. Bone (2013) 56(1):163-73. doi:10.1016/j.bone.2013.05.024

123. Shashkova EV, Trivedi J, Cline-Smith AB, Ferris C, Buchwald ZS, Gibbs J, et al. Osteoclast-primed Foxp3+ CD8 T cells induce T-bet, eomesodermin, and IFN-gamma to regulate bone resorption. J Immunol (2016) 197(3): 726-35. doi:10.4049/jimmunol.1600253

124. Zaiss MM, Sarter K, Hess A, Engelke K, Bohm C, Nimmerjahn F, et al. Increased bone density and resistance to ovariectomy-induced bone loss in FoxP3-transgenic mice based on impaired osteoclast differentiation. Arthritis Rheum (2010) 62(8):2328-38. doi:10.1002/art.27535

125. Kim YG, Lee CK, Nah SS, Mun SH, Yoo B, Moon HB. Human CD4+CD25+ regulatory $\mathrm{T}$ cells inhibit the differentiation of osteoclasts from peripheral blood mononuclear cells. Biochem Biophys Res Commun (2007) 357(4): 1046-52. doi:10.1016/j.bbrc.2007.04.042

126. Axmann R, Herman S, Zaiss M, Franz S, Polzer K, Zwerina J, et al. CTLA-4 directly inhibits osteoclast formation. Ann Rheum Dis (2008) 67(11): 1603-9. doi:10.1136/ard.2007.080713

127. Zaiss MM, Axmann R, Zwerina J, Polzer K, Guckel E, Skapenko A, et al. Treg cells suppress osteoclast formation: a new link between the immune system and bone. Arthritis Rheum (2007) 56(12):4104-12. doi:10.1002/art.23138

128. Bozec A, Zaiss MM, Kagwiria R, Voll R, Rauh M, Chen Z, et al. T cell costimulation molecules CD80/86 inhibit osteoclast differentiation by inducing the IDO/tryptophan pathway. Sci Transl Med (2014) 6(235): 235ra60. doi:10.1126/scitranslmed.3007764

129. Ibanez L, Abou-Ezzi G, Ciucci T, Amiot V, Belaid N, Obino D, et al. Inflammatory osteoclasts prime TNFalpha-producing CD4(+) $\mathrm{T}$ cells and express CX3 CR1. J Bone Miner Res (2016) 31(10):1899-908. doi:10.1002/ jbmr.2868

130. Zou W, Wolchok JD, Chen L. PD-L1 (B7-H1) and PD-1 pathway blockade for cancer therapy: mechanisms, response biomarkers, and combinations. Sci Transl Med (2016) 8(328):328rv4. doi:10.1126/scitranslmed.aad7118

131. Francisco LM, Salinas VH, Brown KE, Vanguri VK, Freeman GJ, Kuchroo VK, et al. PD-L1 regulates the development, maintenance, and function of induced regulatory T cells. J Exp Med (2009) 206(13):3015-29. doi:10.1084/ jem. 20090847

132. Abiko K, Matsumura N, Hamanishi J, Horikawa N, Murakami R, Yamaguchi K, et al. IFN-gamma from lymphocytes induces PD-L1 expression and promotes progression of ovarian cancer. Br J Cancer (2015) 112(9):1501-9. doi:10.1038/bjc.2015.101

133. Liu J, Hamrouni A, Wolowiec D, Coiteux V, Kuliczkowski K, Hetuin D, et al. Plasma cells from multiple myeloma patients express B7-H1 (PD-L1) and increase expression after stimulation with IFN-\{gamma $\}$ and TLR ligands via a MyD88-, TRAF6-, and MEK-dependent pathway. Blood (2007) 110(1):296-304. doi:10.1182/blood-2006-10-051482

134. Sanmamed MF, Chen L. Inducible expression of B7-H1 (PD-L1) and its selective role in tumor site immune modulation. Cancer J (2014) 20(4): 256-61. doi:10.1097/PPO.0000000000000061

135. Tremblay-LeMay R, Rastgoo N, Chang H. Modulating PD-L1 expression in multiple myeloma: an alternative strategy to target the PD-1/PD-L1 pathway. J Hematol Oncol (2018) 11(1):46. doi:10.1186/s13045-018-0589-1

136. Hallett WH, Jing W, Drobyski WR, Johnson BD. Immunosuppressive effects of multiple myeloma are overcome by PD-L1 blockade. Biol Blood Marrow Transplant (2011) 17(8):1133-45. doi:10.1016/j.bbmt.2011.03.011

137. Ray A, Das DS, Song Y, Richardson P, Munshi NC, Chauhan D, et al. Targeting PD1-PDL1 immune checkpoint in plasmacytoid dendritic cell interactions with T cells, natural killer cells and multiple myeloma cells. Leukemia (2015) 29(6):1441-4. doi:10.1038/leu.2015.11

138. Yousef S, Marvin J, Steinbach M, Langemo A, Kovacsovics T, Binder M, et al. Immunomodulatory molecule PD-L1 is expressed on malignant plasma cells and myeloma-propagating pre-plasma cells in the bone marrow of multiple myeloma patients. Blood Cancer J (2015) 5:e285. doi:10.1038/bcj.2015.7

139. Dhodapkar MV, Sexton R, Das R, Dhodapkar KM, Zhang L, Sundaram R, et al. Prospective analysis of antigen-specific immunity, stem-cell antigens, and immune checkpoints in monoclonal gammopathy. Blood (2015) 126(22): 2475-8. doi:10.1182/blood-2015-03-632919

140. Tamura H, Ishibashi M, Yamashita T, Tanosaki S, Okuyama N, Kondo A, et al. Marrow stromal cells induce B7-H1 expression on myeloma cells, 
generating aggressive characteristics in multiple myeloma. Leukemia (2013) 27(2):464-72. doi:10.1038/leu.2012.213

141. Gorgun G, Samur MK, Cowens KB, Paula S, Bianchi G, Anderson JE, et al. Lenalidomide enhances immune checkpoint blockade-induced immune response in multiple myeloma. Clin Cancer Res (2015) 21(20):4607-18. doi:10.1158/1078-0432.CCR-15-0200

142. Wang L, Wang H, Chen H, Wang WD, Chen XQ, Geng QR, et al. Serum levels of soluble programmed death ligand 1 predict treatment response and progression free survival in multiple myeloma. Oncotarget (2015) 6(38): 41228-36. doi:10.18632/oncotarget.5682

143. Sponaas AM, Moharrami NN, Feyzi E, Standal T, Holth Rustad E, Waage A, et al. PDL1 expression on plasma and dendritic cells in myeloma bone marrow suggests benefit of targeted anti PD1-PDL1 therapy. PLoS One (2015) 10(10):e0139867. doi:10.1371/journal.pone.0139867

144. Chen D, Tang P, Liu L, Wang F, Xing H, Sun L, et al. Bone marrow-derived mesenchymal stem cells promote cell proliferation of multiple myeloma through inhibiting T-cell immune responses via PD-1/PD-L1 pathway. Cell Cycle (2018) 17(7):858-67. doi:10.1080/15384101.2018.1442624

145. Tai YT, Acharya C, An G, Moschetta M, Zhong MY, Feng X, et al. APRIL and BCMA promote human multiple myeloma growth and immunosuppression in the bone marrow microenvironment. Blood (2016) 127(25): 3225-36. doi:10.1182/blood-2016-01-691162

146. Driscoll J, Aslam I, Malek E. Eosinophils upregulate PD-L1 and PD-L2 expression to enhance the immunosuppressive microenvironment in multiple myeloma. Blood (2017) 130(Suppl 1):4417.

147. Kelly KR, Espitia CM, Zhao W, Wu K, Visconte V, Anwer F, et al. Oncolytic reovirus sensitizes multiple myeloma cells to anti-PD-L1 therapy. Leukemia (2018) 32(1):230-3. doi:10.1038/leu.2017.272

148. Ray A, Das DS, Song Y, Hideshima T, Tai YT, Chauhan D, et al. Combination of a novel HDAC6 inhibitor ACY-241 and anti-PD-L1 antibody enhances anti-tumor immunity and cytotoxicity in multiple myeloma. Leukemia (2018) 32(3):843-6. doi:10.1038/leu.2017.322

149. Benson DM Jr, Bakan CE, Mishra A, Hofmeister CC, Efebera Y, Becknell B, et al. The PD-1/PD-L1 axis modulates the natural killer cell versus multiple myeloma effect: a therapeutic target for CT-011, a novel monoclonal anti-PD-1 antibody. Blood (2010) 116(13):2286-94. doi:10.1182/blood-201002-271874

150. Giuliani M, Janji B, Berchem G. Activation of NK cells and disruption of PD-L1/PD-1 axis: two different ways for lenalidomide to block myeloma progression. Oncotarget (2017) 8(14):24031-44. doi:10.18632/oncotarget. 15234

151. Li J, Stagg NJ, Johnston J, Harris MJ, Menzies SA, DiCara D, et al. Membraneproximal epitope facilitates efficient $\mathrm{T}$ cell synapse formation by antiFcRH5/CD3 and is a requirement for myeloma cell killing. Cancer Cell (2017) 31(3):383-95. doi:10.1016/j.ccell.2017.02.001

152. Lesokhin AM, Ansell SM, Armand P, Scott EC, Halwani A, Gutierrez M, et al. Nivolumab in patients with relapsed or refractory hematologic malignancy: preliminary results of a phase Ib study. JClin Oncol (2016) 34(23):2698-704. doi:10.1200/JCO.2015.65.9789

153. Mateos MV, Orlowski RZ, Siegel DS, Reece DE, Moreau P, Ocio EM, et al. Pembrolizumab in combination with lenalidomide and low-dose dexamethasone for relapsed/refractory multiple myeloma. J Clin Oncol (2016) 34(15):Abstract8010.

154. Badros A, Hyjek E, Ma N, Lesokhin A, Dogan A, Rapoport AP, et al. Pembrolizumab, pomalidomide, and low-dose dexamethasone for relapsed/ refractory multiple myeloma. Blood (2017) 130(10):1189-97. doi:10.1182/ blood-2017-03-775122

155. von Metzler I, Krebbel H, Hecht M, Manz RA, Fleissner C, Mieth M, et al. Bortezomib inhibits human osteoclastogenesis. Leukemia (2007) 21(9): 2025-34. doi:10.1038/sj.leu.2404806

156. Hongming H, Jian H. Bortezomib inhibits maturation and function of osteoclasts from PBMCs of patients with multiple myeloma by downregulating TRAF6. Leuk Res (2009) 33(1):115-22. doi:10.1016/j.leukres.2008.07.028

157. Qiang YW, Hu B, Chen Y, Zhong Y, Shi B, Barlogie B, et al. Bortezomib induces osteoblast differentiation via Wnt-independent activation of betacatenin/TCF signaling. Blood (2009) 113(18):4319-30. doi:10.1182/blood2008-08-174300

158. Giuliani N, Morandi F, Tagliaferri S, Lazzaretti M, Bonomini S, Crugnola M, et al. The proteasome inhibitor bortezomib affects osteoblast differentiation in vitro and in vivo in multiple myeloma patients. Blood (2007) 110(1):334-8. doi:10.1182/blood-2006-11-059188

159. Oyajobi BO, Garrett IR, Gupta A, Flores A, Esparza J, Munoz S, et al. Stimulation of new bone formation by the proteasome inhibitor, bortezomib: implications for myeloma bone disease. Br J Haematol (2007) 139(3):434-8. doi:10.1111/j.1365-2141.2007.06829.x

160. Terpos E, Heath DJ, Rahemtulla A, Zervas K, Chantry A, Anagnostopoulos A, et al. Bortezomib reduces serum dickkopf-1 and receptor activator of nuclear factor-kappaB ligand concentrations and normalises indices of bone remodelling in patients with relapsed multiple myeloma. $\mathrm{Br} J$ Haematol (2006) 135(5):688-92. doi:10.1111/j.1365-2141.2006.06356.x

161. Mukherjee S, Raje N, Schoonmaker JA, Liu JC, Hideshima T, Wein MN, et al. Pharmacologic targeting of a stem/progenitor population in vivo is associated with enhanced bone regeneration in mice. JClin Invest (2008) 118(2):491-504. doi:10.1172/JCI33102

162. Breitkreutz I, Raab MS, Vallet S, Hideshima T, Raje N, Mitsiades C, et al. Lenalidomide inhibits osteoclastogenesis, survival factors and boneremodeling markers in multiple myeloma. Leukemia (2008) 22(10):1925-32. doi:10.1038/leu.2008.174

163. Bolzoni M, Storti P, Bonomini S, Todoerti K, Guasco D, Toscani D, et al. Immunomodulatory drugs lenalidomide and pomalidomide inhibit multiple myeloma-induced osteoclast formation and the RANKL/OPG ratio in the myeloma microenvironment targeting the expression of adhesion molecules. Exp Hematol (2013) 41(4):387-97.e1. doi:10.1016/j.exphem.2012.11.005

164. Berenson JR, Lichtenstein A, Porter L, Dimopoulos MA, Bordoni R, George S, et al. Efficacy of pamidronate in reducing skeletal events in patients with advanced multiple myeloma. Myeloma Aredia Study Group. N Engl J Med (1996) 334(8):488-93. doi:10.1056/NEJM199602223340802

165. Rosen LS, Gordon D, Kaminski M, Howell A, Belch A, Mackey J, et al. Zoledronic acid versus pamidronate in the treatment of skeletal metastases in patients with breast cancer or osteolytic lesions of multiple myeloma: a phase III, double-blind, comparative trial. Cancer J (2001) 7(5):377-87.

166. Hughes DE, Wright KR, Uy HL, Sasaki A, Yoneda T, Roodman GD, et al. Bisphosphonates promote apoptosis in murine osteoclasts in vitro and in vivo. J Bone Miner Res (1995) 10(10):1478-87. doi:10.1002/jbmr.5650101008

167. Plotkin LI, Weinstein RS, Parfitt AM, Roberson PK, Manolagas SC, Bellido T. Prevention of osteocyte and osteoblast apoptosis by bisphosphonates and calcitonin. J Clin Invest (1999) 104(10):1363-74. doi:10.1172/JCI6800

168. Dempster DW, Lambing CL, Kostenuik PJ, Grauer A. Role of RANK ligand and denosumab, a targeted RANK ligand inhibitor, in bone health and osteoporosis: a review of preclinical and clinical data. Clin Ther (2012) 34(3):521-36. doi:10.1016/j.clinthera.2012.02.002

169. Hanley DA, Adachi JD, Bell A, Brown V. Denosumab: mechanism of action and clinical outcomes. Int J Clin Pract (2012) 66(12):1139-46. doi:10.1111/ ijcp. 12022

170. Kostenuik PJ, Nguyen HQ, McCabe J, Warmington KS, Kurahara C, Sun N, et al. Denosumab, a fully human monoclonal antibody to RANKL, inhibits bone resorption and increases BMD in knock-in mice that express chimeric (murine/human) RANKL. J Bone Miner Res (2009) 24(2):182-95. doi:10.1359/jbmr.081112

171. Raje N, Terpos E, Willenbacher W, Shimizu K, Garcia-Sanz R, Durie B, et al. Denosumab versus zoledronic acid in bone disease treatment of newly diagnosed multiple myeloma: an international, double-blind, doubledummy, randomised, controlled, phase 3 study. Lancet Oncol (2018) 19(3): 370-81. doi:10.1016/S1470-2045(18)30072-X

172. Atanackovic D, Steinbach M, Radhakrishnan SV, Luetkens T. Immunotherapies targeting CD38 in multiple myeloma. Oncoimmunology (2016) 5(11): e1217374. doi:10.1080/2162402X.2016.1217374

173. Costa F, Toscani D, Chillemi A, Quarona V, Bolzoni M, Marchica V, et al. Expression of $\mathrm{CD} 38$ in myeloma bone niche: a rational basis for the use of anti-CD38 immunotherapy to inhibit osteoclast formation. Oncotarget (2017) 8(34):56598-611. doi:10.18632/oncotarget.17896

174. Khunger M, Rakshit S, Pasupuleti V, Hernandez AV, Mazzone P, Stevenson J, et al. Incidence of pneumonitis with use of programmed death 1 and programmed death-ligand 1 inhibitors in non-small cell lung cancer: a systematic review and meta-analysis of trials. Chest (2017) 152(2):271-81. doi:10.1016/j.chest.2017.04.177

175. Berdeja JG, Lin Y, Raje N, Munshi N, Siegel D, Liedtke M, et al. Durable clinical responses in heavily pretreated patients with relapsed/refractory 
multiple myeloma: updated results from a multicenter study of bb2121 anti-Bcma CAR T cell therapy. Blood (2017) 130(Suppl 1):740.

176. Vogl DT, Raje N, Jagannath S, Richardson P, Hari P, Orlowski R, et al. Ricolinostat, the first selective histone deacetylase 6 inhibitor, in combination with bortezomib and dexamethasone for relapsed or refractory multiple myeloma. Clin Cancer Res (2017) 23(13):3307-15. doi:10.1158/1078-0432. CCR-16-2526

177. Kelly KR, Wu K, Tsao-Wei D, Groshen S, Triche TJ, Mohrbacher A, et al. Oncolytic reovirus immune priming: a phase $1 \mathrm{~b}$ study of reolysin with bortezomib and dexamethasone in patients with relapsed/refractory multiple myeloma. Blood (2016) 128(22):4507.

178. Ahern E, Harjunpaa H, Barkauskas D, Allen S, Takeda K, Yagita H, et al. Co-administration of RANKL and CTLA4 antibodies enhances lymphocyte-mediated antitumor immunity in mice. Clin Cancer Res (2017) 23(19):5789-801. doi:10.1158/1078-0432.CCR-17-0606

179. Ahern E, Harjunpää H, O’Donnell JS, Allen S, Dougall WC, Teng MWL, et al. RANKL blockade improves efficacy of PD1-PD-L1 blockade or dual
PD1-PD-L1 and CTLA4 blockade in mouse models of cancer. Oncoimmunology (2018) 7:e1431088. doi:10.1080/2162402X.2018.1431088

Conflict of Interest Statement: KA serves on advisory boards Celgene, Millennium and Gilead Sciences and is a Scientific founder of OncoPep and C4 Therapeutics. P. Richardson is on advisory board of Celgene, Millennium and Johnson \& Johnson. The remaining authors declare that the writing and research was conducted in the absence of any commercial or financial relationships that could be construed as a potential conflict of interest.

Copyright $\odot 2018$ Tai, Cho and Anderson. This is an open-access article distributed under the terms of the Creative Commons Attribution License (CC BY). The use, distribution or reproduction in other forums is permitted, provided the original author(s) and the copyright owner(s) are credited and that the original publication in this journal is cited, in accordance with accepted academic practice. No use, distribution or reproduction is permitted which does not comply with these terms. 